Illinois State University

ISU ReD: Research and eData

Theses and Dissertations

7-16-2021

\title{
The Significance of Significance: Decolonizing Cultural Resource Management Practices in the Upper Midwest
}

JUSTIN Allen WOODS

Illinois State University, Tehcubsfan@gmail.com

Follow this and additional works at: https://ir.library.illinoisstate.edu/etd

\section{Recommended Citation}

WOODS, JUSTIN Allen, "The Significance of Significance: Decolonizing Cultural Resource Management Practices in the Upper Midwest" (2021). Theses and Dissertations. 1480.

https://ir.library.illinoisstate.edu/etd/1480

This Thesis is brought to you for free and open access by ISU ReD: Research and eData. It has been accepted for inclusion in Theses and Dissertations by an authorized administrator of ISU ReD: Research and eData. For more information, please contact ISUReD@ilstu.edu. 


\section{THE SIGNIFICANCE OF SIGNIFICANCE: DECOLONIZING CULTURAL RESOURCE MANAGEMENT PRACTICES IN THE UPPER MIDWEST}

\section{JUSTIN WOODS}

\section{Pages}

Indigenous communities across the United States were coerced and tricked into signing treaties that ceded significant portions of their ancestral lands. This land holds cultural value in many ways? to the tribal members, however academics and archaeologists who do not often share these values determine their cultural and historical significance due to federal and often state law, evaluations that have important economic, political, and social consequences for the local communities. This research analyzes examples from cultural resource management (CRM) case studies in the Northern Great Lakes Region of Wisconsin, Michigan, North and South Dakota and Minnesota to evaluate (1) consultation procedures with Indigenous tribes in the region for assessing cultural resource values; (2) the criteria for determining significance; (3) accessible, published evidence of significance of the project regions for Indigenous stakeholders; (4) local impacts of the archaeological decision making. Methodologies for evaluating CRM reports include a critical analysis of descriptive language terms and content analysis as well as re-contextualization of archaeological results within Indigenous-centered frames of reference. Published historical accounts as well as public statements by Indigenous community members offer such frames of reference, as a way to bring indigenous voices back into the research and offer new interpretations of the results. Results show that the language and criteria for determining significance of these reports is biased, colonizing, and racist in a way that negates 
many closely held Indigenous belief systems. Indigenous communities within the Upper Midwest have seen numerous CRM projects that have not only ignored their ideologies and beliefs on the local resources but have actively destroyed them. The determinations of significance in CRM work on Indigenous lands have had important consequences and, in some cases, even destroyed the landscape. This thesis adds a new layer of understanding, and actively works to decolonize CRM practices, and bring indigenous voices into contract archaeology.

KEYWORDS: Great Lakes Region; Upper Midwest; Cultural Resource Management; Contract Archaeology 
THE SIGNIFICANCE OF SIGNIFICANCE: DECOLONIZING CULTURAL RESOURCE MANAGEMENT PRACTICES IN THE UPPER MIDWEST

\author{
JUSTIN WOODS
}

\author{
A Thesis Submitted in Partial \\ Fulfillment of the Requirements \\ for the Degree of \\ MASTER OF SCIENCE \\ Department of Sociology and Anthropology \\ ILLINOIS STATE UNIVERSITY
}

2021 
(C) 2021 Justin Woods 
THE SIGNIFICANCE OF SIGNIFICANCE: DECOLONIZING CULTURAL RESOURCE MANAGEMENT PRACTICES IN THE UPPER MIDWEST

\author{
JUSTIN WOODS
}

COMMITTEE MEMBERS:

Kathryn Sampeck, Chair

\author{
G. Logan Miller
}




\section{ACKNOWLEDGMENTS}

I would like to express my gratitude and appreciate for everyone who helped make this thesis possible. A special thanks to Dr. Katie Sampeck for her guidance, assistance and expertise when approaching this research. Thank you for giving me the opportunity to pursue this dream of archaeology, and for encouraging me to expand beyond my comfort zone. A special thank you to Dr. Logan Miller for joining my committee on such short notice and being such an invaluable asset to my thesis research. Without your assistance and guidance, I would not have been able to complete my research in time. I lastly would like to thank Kelsey, my parents and all of my Friends with thin the ISU Department of Anthropology and Sociology for their support and for challenging me to continuously improve and finish within the expedited timeline.

J.W. 


\section{CONTENTS}

Page

ACKNOWLEDGMENTS

$\begin{array}{ll}\text { CONTENTS ii } & \text { ii }\end{array}$

FIGURES

CHAPTER I: INTRODUCTION 1

$\begin{array}{ll}\text { Evaluating Historical Significance } & 1\end{array}$

$\begin{array}{ll}\text { Peoples and Places in this Study } & 6\end{array}$

$\begin{array}{ll}\text { Tribal Nations Present in the Reports } & 7\end{array}$

The Sahnish (Arikara) (Sturevant, 1978) $\quad 8$

Očhéthi Šakówin (Sioux) (Sturevant, 1978) 99

Hidatsa (Sturevant, 1978) 11

Rųwą́?ka·ki (Mandan) (Sturevant, 1978) 12

Chahiksichahiks (Pawnee) (Sturevant, 1978) 13

Anishinaabe (Ojibwe) (Sturevant, 1978) 14

Wendat (Huron) (Sturevant, 1978) 15

The OӨaakiiwaki (Sauk) and Meskwaki (Fox) (Sturevant, 1978) 16

$\begin{array}{ll}\text { Ancient Cultural Traditions (Sturevant, 1978) } & 17\end{array}$

$\begin{array}{ll}\text { The Middle Missouri (Sturevant, 1978) } & 18\end{array}$

The Coalescent Tradition (Sturevant, 1978) 19

CHAPTER II: THEORETICAL FRAMEWORK 21

Theoretical Approaches of CRM Examples $\quad 21$

Theoretical Approaches for This Study 22 
$\begin{array}{ll}\text { Action Anthropology Theory } & 22\end{array}$

$\begin{array}{ll}\text { Indigenous Critique } & 24\end{array}$

$\begin{array}{ll}\text { Indigenous Archaeology } & 25\end{array}$

$\begin{array}{ll}\text { Decolonizing Theory } & 26\end{array}$

$\begin{array}{ll}\text { CHAPTER III: METHODOLOGY } & 30\end{array}$

$\begin{array}{ll}\text { Evaluation Methods } & 30\end{array}$

$\begin{array}{ll}\text { Content Analysis } & 31\end{array}$

Re-Contextualization of Archaeological Data 32

Assessing Tribal Significance of Project Regions 33

$\begin{array}{ll}\text { Local Impacts } & 35\end{array}$

CHAPTER IV: CASE STUDIES 36

$\begin{array}{ll}\text { Michigan } & 39\end{array}$

$\begin{array}{ll}\text { Minnesota } & 51\end{array}$

$\begin{array}{ll}\text { North Dakota } & 56\end{array}$

$\begin{array}{ll}\text { South Dakota } & 60\end{array}$

$\begin{array}{ll}\text { Wisconsin } & 77\end{array}$

$\begin{array}{ll}\text { Collaborative Reports } & 82\end{array}$

Anishinaabe (Ojibwe) Examples $\quad 84$

Discussion of Results $\quad 92$

CHAPTER V: DISCUSSION AND CONCLUSIONS 93

$\begin{array}{ll}\text { North and South Dakota } & 94\end{array}$

$\begin{array}{ll}\text { Michigan } & 96\end{array}$

$\begin{array}{ll}\text { Minnesota } & 99\end{array}$ 
Wisconsin

Collaborative Reports

Conclusions

103

REFERENCES

106 


\section{FIGURES}

Figure $\quad$ Page

$\begin{array}{ll}\text { 1. Overview Map } & 37\end{array}$

2. Map of the Great Lakes Region (Michigan, Minnesota, and Wisconsin) 38

3. Great Plains Overview 


\section{CHAPTER I: INTRODUCTION}

In this thesis, I evaluate cultural resource management reports from the upper Midwest, especially the Great Lakes Region: Michigan, Minnesota, North Dakota, South Dakota, and Wisconsin, to analyze the authors' decisions for including or excluding details pertaining to Indigenous tribal communities that were living in the project regions during any time period. These reports were done to comply with federal cultural heritage preservation laws. The decisions of archaeologists were important for determining areas of development or alteration versus conservation or avoidance and thus have a great deal of impact in the management of lands and even the way people interact with the area well after the initial decision making. In 1966, Congress enacted the National Historic Preservation Act. Within this legislation, Section 106 mandates that the federal government must complete archaeological work in search of and in preservation of cultural materials before any federally funded development. "A project, activity, or program either funded, permitted, licensed, or approved by a federal agency.” Which is any federally funded project, or project located on any federal lands. "May Take place on or off

federally controlled property and include new and continuing projects, activities or programs. (36 CFR 800.3, 800.16). How did this federal mandate take into consideration community values when they determined something as important as "significance"?

\section{Evaluating Historical Significance}

The National Register of Historic Places is one of the key components of the National Historic Preservation act. In the law, it creates and further mandates inclusion to the National Register of Historic Places, working to preserve items of national and cultural heritage (36 CFR 60). Qualifying for the National Register involves a high ranking in four main criteria: (1) event, which the property must contribute to major pattern of American history or must have taken part 
of the event. This can range from a location of an event, such as a Woodstock, or a place of historical significance such as the National Mall. This second criterion is person, which is associated with a significant person of the past. This can be a birthplace, death place, or residency. The third criterion is design or construction, which is primarily architecture and construction. Examples for this could be architectural such as Frank Lloyd Wright's buildings. The last one, and the most important for the sake of this paper, is Criterion D or information potential. It is through this informational potential that archaeologists can assess significance and make the judgement as to whether or not the site should be preserved based on its potential to add to the overall knowledge of a region or specific cultural group.

Within the fourth criteria, information potential, significance is a crucial criterion. Significance in this context is the information potential of archaeological evidence. Can it improve our knowledge? Does it offer unique or interesting data? Does it change our understanding? Is it of cultural importance? In CRM or contract archaeology, work is done to comply with federal and state laws, significance is a word that is very fluid in meaning. No specific federal guidelines exist for assessing significance, as no defined meaning of significance exists within the law. It was purposefully written to be vague, which leads to a discrepancy among archaeologists as to how they should approach evaluating significance.

The issues surrounding significance are immense. Ascribing significance to a place of spiritual and sacred origins can get messy depending on how you go about it. The legal realm avoids assessing religious beliefs because it may favor certain aspects of a religious doctrine. (King 2004, 122). Even further, a loophole exists with potentially eligible places. The archaeologist conducting the evaluation can say that a property may be potentially eligible for the register, however in the eyes of the law this is not anything more than a possible 
recommendation for further study. In short, properties that archaeologists see as potentially eligible can be destroyed and not properly preserved because it does not fit within the binary system of eligible or noneligible. (King 2004, 128).

Archaeologists determine significance based on their interpretations of their archaeological investigation, which in the majority of cases is pedestrian survey. An archaeological survey is a research methodology in which an archaeologist searches a predefined region to recover evidence of physical alterations and objects. The limits of many CRM projects are limited based upon geographic region, whether it be the extent of the development project or the extent of a geographic feature being studied. Most CRM teams consist of field technicians who at a minimum have the experience of at least a field school and six months of archaeological work. Many CRM archaeologists are either in-house (employed by the federal or state agency) or contracted by a company who is actively seeking to develop the land.

The results of the survey process determine whether a development or other grounddisturbing project can proceed as planned or must be changed to make it possible for contexts to be preserved in perpetuity. Many factors can impact the result of a survey, such as ground conditions, preservation quality or even external soil disturbances. Other facts that could affect development would be the location of an archaeological site, and if that site is deemed significant may protect it against developments, or require mitigation excavations.

Assessing significance in terms of a Section 106 definition is left open-ended. A series of publications on assessing significance of archaeological sites, as a pre-requisite of the National Register of Historic Places, offer interpretations or best practices from a cultural resource management perspective (Klein, 1999). One of the topics in these publications deals with Indigenous related sites and how best to approach them (Atalay, 2007). None of them directly 
acknowledge that all lands within the United States are indigenous, nor do they offer specific approaches as to how to deal with indigenous lands.

For several years after the 1966 law was enacted, the most common practice among CRM archaeologists was to assume that a site provided new knowledge that can contribute positively to the overarching whole and added a new depth of information. This can be a great way to begin, but years down the line, as we build a catalog of archaeological sites, it can become a limiting factor for new sites to be considered significant. (Klein, 1999) Over time, as archaeologists discover and locate new sites, they have to be anomalous compared to the preestablished knowledge. This baseline of recorded sites actually prevents more newly discovered sites from being considered. Furthermore, even sites that may be like already recorded ones have information potential because of their state of preservation, variety of artifact assemblages, artifact densities, or even their location. This potential knowledge could and would be lost if the site is not determined to be significant and considered ineligible for further preservation by being listed on the National Register of Historic Places.

The specific situation of historic homesteads has the same problems; ideas of significance include decision making on a case-by-case basis with minimal effort to determine their regional context. To expand beyond just a single site into a regional context would be necessary to make the determination. Each instance of significance would need to be compared to a regional pattern to make a valid determination (Wilson, 1990).

Standard practices for determining significance are ambiguous because many CRM archaeologists base their judgment of significance on artifact densities or overall site preservation. The archaeologist often makes such judgements by themselves, and it is this judgement, which is only overseen by higher ups in CRM firms or even state archaeologists, that 
decides the fate of site preservation. Rarely does an Indigenous person occupy those positions of power, yet they are most able to see discrepancies in the way determination is made and evidence of a non-Indigenous bias (Mihesuah,1998: 93). This lack of outside perspective makes the archaeological determinations even more flawed.

These points underscore that no uniform process exists in which archaeologists make the determination in the most unbiased way possible. This implication is even more problematic as personal biases can become an implicit way to affect preservation. Prehistoric focused archaeologists will devote more time and effort to prehistoric contexts, and historical archaeologists likewise to a historic component. (Lightfoot, 1995) Indigenous academics argue that this same bias can affect non-Indigenous archaeologists' determinations of an Indigenous site. (Mihesuah and Wilson, 1998)

Because of these concerns about the standards for significance, Indigenous communities have communicated that they feel as though the archaeologists conducting the survey, writing the reports, and making significance determinations do not properly take their view of what is significant into account. These Indigenous communities argue that their land holds significance based on the knowledge, beliefs, and origin stories of the tribe, and in local native resources central to tribal identity and everyday life, such as wild rice and birch trees in the case of the Anishinaabe (discussed in more detail in Chapter IV) (Matson et. Al, 2021). The foundation on which Indigenous significance gains its significance is based on the origin stories and religious beliefs of the tribe. This directly contradicts the archaeologist's vision of significance based on an information potential. (King, 2004) This discrepancy between education and religion is what leads to the differing opinions between the two groups. The fundamental concept and operating 
principle of significance needs to be decolonized so that it does not support further colonization and actively works against it. (Sunseri and Gonzalez, 2020).

\section{Peoples and Places in this Study}

These lands under study have all had a history of moving and shifting tribal caretaking and have witnessed numerous mass migrations of people both in and out of the region. North Dakota and South Dakota were the ancestral lands of the Sahnish, Rųwąakka ki and Hidatsa before the Očhéthi Šakówin and Anishinaabe had migrated farther west after expansion in the East by the European Colonial settlers, had forced them out. The Sahnish originally occupied the land south of the Big Bend in the Missouri River, just south of what is modern day Pierre, South Dakota. Due to northern migrations by the Očhéthi Šakówin they were forced farther north, up the Missouri River basin, until they ended up in North Dakota where they joined with the Hidatsa and Rųwą́?ka·ki. The Hidatsa and Rųwą́?ka·ki occupied parts of North and South Dakota and focused primarily on hunting, remaining semi-nomadic well into the 1900s The Rųwą́?ka·ki, Hidatsa, and Sahnish faced pressure from the Očhéthi Šakówiy, who had migrated into the region. (Sturtevant, 1978) This growing density in settlement increasingly strained the landscape. Plus, settler colonial activities actively depleted the resources that these Native American communities relied upon. In Minnesota and Wisconsin, the Očhéthi Šakówin were pushed further east by the incoming Anishinaabe. The Anishinaabe faced external pressures, as Europeans migrated further inland from their coastal colonial settlements from the east that forced the Anishinaabe westbound. This movement also ties into Anishinaabe origin stories: as they were migrating, they were searching for the land where food grows on water (Katanski, 2017)). When they ended up in the Great Lakes region, they found wild rice beds growing on the water. Each of these groups now resides in these regions, however since the $19^{\text {th }}$ century, many 
have been shifted to live on tribal reservations as many European settlers took the Indigenous lands through a series of malicious land grab treaties and force.

This displacement of tribal groups can be easily identified on the basis of cultural characteristics, defensive fortifications, and remains from conflicts included in the reports. Each of the groups mentioned faced even further pressures as the seventeenth- and eighteenth-century fur trade shifting farther west over time. Native American communities chased the fur-yielding animals and created new splinter factions as some groups partnered with the fur traders, others acted as intermediaries, and some were expelled altogether (Sturtevant, 1978).

The question of this thesis is: does interpretation of the archaeological materials change when it is viewed from an Indigenous perspective? How does this Indigenous-centered evaluation affect the assessment of the significance of archaeological resources? To analyze this question, I examined 26 CRM reports. The reports I selected are from a collection of archaeological site reports investigating many areas in the upper Midwest region of the United States. The reports center around the geographic region of the Upper Midwest, focusing on region rather than tribal or cultural affiliations. These reports, which dates from the 1930s to the 2010s, offer a range of dates of publication that give a view into shifting perspectives within the field. The reports are meant to give a meaningful sample of both content and in interpretation of their results for this area.

\section{Tribal Nations Present in the Reports}

In this research there are nine tribal nations represented. Each of which has their own origin stories and backgrounds that will be further discussed below. Each account was derived from the ethnographic sources compiled by Sturtevant in 1978 as a part of the Smithsonian's Handbook of North American Indians. The research will focus mainly on the tribal nations' 
origin stories as the basis of the re-interpretation and focus of indigenous perspectives and as such, the follow sections will provide the necessary background to understand the reinterpretations.

\section{The Sahnish (Arikara) (Sturtevant, 1978)}

For the Sahnish, landscape is held to be sacred. The Sahnish origin story starts with Chief Above, who first lived underground. With the intercession of Mother Corn, people came up out of the ground and traveled a path laden with obstacles that they overcame. In each Sahnish village a shrine was erected with a sacred bundle that sanctioned the organization of the village and formed the basis of social order, including the chief who was the descendant of the creator of the bundle. The bundle always contained five large gourd rattles, along with four perfect ears of corn, a calumet pipe, and braids of sweetgrass as well as skins of birds. The keeper kept the bundles safe and guarded but did not know the rituals associated. That was left to the priest of the village. Villages worked as a form of large-scale kinship; each earth lodge was an extended family that was matriarchal. For burials, all bodies were oriented to the east; men were buried with their weapons and women with their tools.

Location of villages was carefully selected and planned. Each village had a center building significantly larger than residential housing that was for ceremonies and large village gatherings. The location of the village also took into consideration maize agriculture.

They were able to cultivate the lowlands near the river and have farming plots farther out. They cultivated 11 different types of maize. Once people planted the maize, they left the plantings to mature while the tribe conducted their annual summer buffalo hunt, returning when

the corn was ready for harvest. Trade became a primary focus for the Sahnish during the late $18^{\text {th }}$ and early $19^{\text {th }}$ century (1700-1800 A.D.) Women were in charge of farming and bartering their 
crop. As they traded more and more, they became less nomadic. Their part as middlemen for trade lead to the further dispersal of horses as they traded them from the west to tribes in the north and east. It was common for an Očhéthi Šakówin group to camp outside of the Sahnish village for the entire winter, carrying on constant trade. However, when the Očhéthi Šakówin could not trade meat or skins and suffered from hunger, they forced the Sahnish to provide them corn, leading to hostility between the groups. The seasonal hunt began waning as the aggressive Očhéthi Šakówin restricted their lives to the immediate vicinity of their village.

\section{Očhéthi Šakówiy (Sioux) (Sturtevant, 1978)}

Unlike the Sahnish, Očhéthi Šakówin observe many permanent groups and subgroups based on region and kinship. The three main divisions of Očhéthi Šakówin are the Santee, Yankton and Yanktoni, and the Teton. Each one represents a different sub-group of Očhéthi Šakówin.

The name Santee, coined by the Teton Očhéthi Šakówin, is an inclusive term for the Eastern Očhéthi Šakówin. It combines the Sisseton, Wahpeton, Mdewakanton, Wahpekute into one term, Santee. Despite their unification, each group has their own cultural traditions and did not work as a cohesive unit. The Santee often worked as middlemen between the Teton and Yankton-Yanktonai, meeting in prearranged locations.

Both the Yankton and Yanktoni speak the same singular dialect of Očhéthi Šakówin. The Yanktoni are divided into two groups: the Lower Yanktonai and the Upper Yanktonai. The Lower Yanktonai are composed of a single band, while the upper Yanktonai has three bands. In terms of cultural practices, the Yankton resemble the Teton due to close association, while the Yanktonai show stronger similarities with Plains Anishinaabe and Cree. 
Lastly is the Teton, who speak Lakȟ́tiyapi. The origin of the Očhéthi Šakówin as a people is relates to the story of the gifted sacred pipe. In the distant past during a time of famine, a beautiful woman carrying a bundle appeared to two young men who were on a hunt. One of the men did not understand that she was a spirit and when he made an unwarranted sexual advance, she turned him into a skeleton. The other man understood this meaning and returned to his village where she visited. She handed her bundle to the chief; it held the first pipe, which was meant to be used as a form of prayer. Smoking the pipe allowed the spirits to hear the prayer and send buffalo.

The Santee were transhumant and foraged for subsistence. They hunted buffalo as a main source of food; however, as they were pushed farther west, deer became the main hunting staple. Fish and waterfowl were other game eaten. They gathered fruit, wild beans, tubers, collected acorns and other nuts, wild rice, and tapped for maple sap. Horticulture of maize, beans and squash was a secondary form of food production. Yields gave enough food for only a few weeks. In contrast, other subgroups of the Očhéthi Šakówin have permanent villages that they left during the summer while buffalo hunting. They subsisted heavily on the buffalo hunting and uniquely used a rabbit hunting stick akin to those found in the American southwest. Each camp traveled independently but would convene during the summer for the buffalo hunt and for the Sun Dance. Subsistence focused heavily on buffalo and other larger game such as elk, blacktailed deer, white-tailed deer, pronghorn, and big horn sheep. Fruits and vegetables were primarily gathered or were acquired by trade with the Sahnish. Unlike the Teton, fishing was of great importance to the Yankton and Yanktonai, and they had their own technique called Hopasipi or fish crowding, where men would drive the fish into narrow inlets making them easier to catch by hand. They also practiced horticulture, cultivating three kinds of maize, two 
types of squash, and three types of beans. Their subsistence relied on these three different types of crops, doubled with their semi-annual buffalo hunts that would provide the necessary food to sustain the village.

Their origin story focuses on the underwater being, so shallow lakes and aquatic foods hold high importance. Their beliefs stem from a vision experience in which spirits would appear in front of them and bestow a power or gift. This spirit vision tied into other messages or significance rituals. Such as the creation of bundles that would not only represent specific bands of the tribe, but also would be an individual and familial marker, usually holding items that would be considered sacred to this meaning.

Power and position within this group was hereditary, meaning it was not achieved but instead based on inheritance. The Chief was chosen through consensus and ideally was someone who put the tribe and others before himself.

\section{Hidatsa (Surtevant, 1978)}

The Hidatsa are related to the Apsáalooke (Crow), as they both speak Siouan languages. The Hidatsa have three separate social divisions: the Awatixa, the Awaxawi and the Hidatsa proper. Each one speaks a distinctive dialect that inform distinct customs. The Awatixa always resided on the Missouri River. The Hidatsa suffered from the smallpox epidemic in 1781, which

left them with half their original population. They were constantly under attack by the Dakota, so they formed an alliance with the Rųwą́ $\mathrm{ka} \cdot \mathrm{ki}$ — as both groups suffered heavy losses—and worked together to survive.

Two oral traditions mark the beginning of the world and origin for the Hidatsa. The first creator story begins with a diving bird who brought up mud from below the waters that the first creator fashioned into land. The first creator took spirits that were living in the underworld and 
caused them to come to the surface and scattered them across the land as different tribes. The story of the Sacred Arrows takes place entirely within the Missouri River. It begins with the story of a Charred Body who heard the bellowing of buffalo and saw the earth from a hole in the sky. He descended to the earth in the form of an arrow, near the Painted Woods. He built a village and brought down 13 couples to populate the village. The myth later discusses the Lodge Boy and Spring Boy, who were twins that were prematurely torn from Charred Body's sister's body. The Hidatsa believed that self-inflicted torture, whether that be taking off part of a finger or fasting, was an offering to a spirit that could increase a person's power. (Sturtevant, 1978)

\section{Rųwą?ka·ki (Mandan) (Sturtevant, 1978)}

The Rųwą́ ka·ki were similar to the Hidatsa in that they were a much larger nation until disease and then further harassment from outside forces reduced them to small sedentary villages. They allied themselves with the Hidatsa for protection and security. Both groups relied upon each other to decide whether or not to go to war.

Their origin story is focuses on the ancestral Corn People, who emerged from under the earth near a body of water that is sometimes considered to be the mouth of the Mississippi. They came up to the earth's surface by climbing a grapevine until it broke under the weight of a pregnant woman. They eventually moved northwards, migrating up the Missouri River.

A second origin story describes how the ancestral buffalo people were created near the middle of the Missouri River. The First Creator made the earth out of mud brought to him from below the waters by an aquatic bird. At the mouth of the Heart River, First Creator and Lone Man made the first sacred pipes which were offered to the animals. Tobacco was the gift of the buffalo who taught Lone Man who to smoke it, and the Lone Man created the ancestral Mandan 
Buffalo People by taking the right rib and making men, and his left rib to make women. They held similar beliefs about power as many groups of this region; they believed power could be gained by a vision quest or through the purchase of a tribal bundle.

The subsistence for the Rųwą́?ka·ki were similar to previously discussed tribal groups as they farmed maize, squash and beans and hunted to help sustain themselves. They acted as middle men for trade, often trading agriculture products to non-agricultural tribes.

\section{Chahiksichahiks (Pawnee) (Sturtevant, 1978)}

The Sahnish (previously mentioned) appear to have been referred to in the past as "the Northern Chahiksichahiks," so it is possible that they were a colony of the Chahiksichahiks or a band that separated and interacted with groups to the north, which resulted in a separate tribal entity.

Their belief systems are similar to other groups of the region in their focus on power and sacred bundles that offer powers to humans. Each village contains a sacred bundle that offers identity and power for the members, and it contains the history and other paraphernalia for performing ceremonies. They are distinctive in their belief in underground or underwater animal lodges where animals live as the Chahiksichahiks do in their lodges.

The Chahiksichahiks are a sedentary group that focuses on a mixed economy of horticulture and hunting. They have permanent villages that they left twice a year on semi-annual bison hunts. They cultivated maize as their staple crop. The white flour breed known as "holy corn" is a crucial item in sacred bundles. Beyond corn, they grow squash, pumpkins, beans melons, and sunflowers. Most of the farming took place on family garden plots, while maize was grown in the hills, tended to twice-prior to leaving for the buffalo hunt. The summer hunt begins earlier in the summer, usually in June and July, while the winter hunt began in October or 
November, usually after the harvest. With the exception of the elderly or ill, the entire village set out on the communal hunt. They supplemented their hunt and harvest with gathering of nuts, berries, seeds, and wild vegetables.

\section{Anishinaabe (Ojibwe) (Sturtevant, 1978)}

The Anishinaabe form one of the largest tribes north of Mexico and have historically occupied lands in Ontario north of Lake Superior and the Wendat. However, once French settlers intensive fur trade moved into the Great Lakes region, the Anishinaabe migrated westward. They established good relations with the French, as intermarrying and trade had fostered positive relationships between the two groups. However, this led to strained relationships with the British; the Anishinaabe were so closely partnered with the French they would actively work against the British until the French surrendered. The migration westward had led to a significance increase in intertribal warfare between the Očhéthi Šakówin and the Anishinaabe. The Anishinaabe moved into Wisconsin, Minnesota and eventually the Dakotas in their quest west. This typically small, intervillage conflict involved a war party forming, raiding a village, and then disbanding upon their return home. The basis of their migration west was a vision of a spirit that gave the guidance to the spiritual leaders of the tribe and told them to go west and find the land where food grows on the water, conditions they found in the Great Lakes Region.

This new ecology marked a shift in their subsistence patterns from a transhumant way of life to a semi-nomadic system. They followed the shifting nature of the resources: in the summer, the focus was on fishing and gathering of wild foods and occasionally some small-scale farming of corn, beans and squash. During the fall they harvested wild rice and perform a ceremony of thanks for the first fruits and harvest. In the springtime, they tapped sugar maple trees to harvest the sap. Tobacco is important to the Anishinaabe, which would be used and smoked during 
ceremonies and celebrations. Smoking was usually accompanied by a prayer, and the smoke would ascend to the spirits. Tobacco was also placed in water before wild rice was harvested, smoked by a warrior before a war party, or was used as an invitation to a feast or party.

\section{Wendat (Huron) (Sturtevant, 1978)}

The Wendat speak a Northern Iroquoian language and live in Western Michigan and parts of Ontario. Wendat spiritual beliefs emphasize that all things have a soul or spirit and the more powerful of the spirits control the daily lives of people. The most powerful of these spirits is that of the sky, as it controls the seasons, winds, and waves along with all of the other climatological and Ecological phenomena. The sky spirit was invoked at special occasions such as healing or treaty signings. Since animals too have spirits, the Wendat are careful not to offend them accidentally, so they do not burn animal and fish bones nor are these remains fed to dogs. Some of the spirits can appear in human form. (Sturtevant, 1978).

Wendat attitudes toward death is not of fear but rather a continuation of life beyond the realm of living. During the period following death, members of the village and friends from outside villages would offer gifts to the death, and they were considered to be expensive affairs. Most bodies were buried temporarily, for up to 8 to 12 years until a feast of the dead occurred. When the feast was coming near, a date was established by tribal elders and families were responsible for the preparations of their relatives remains. To prepare the bodies, they were disinterred from their original resting spot, cleaned of the flesh, which was burned. During the feast of the dead the bodies would be placed in a mass grave, and a ceremony would be held in honor of the deceased. 
The Wendat subsisted on a mixed economy of agriculture, farming maize, beans and squash and by fishing. They would go hunting during the fall and winter months. They were efficient farmers and would focus the majority of their subsistence strategies on agriculture.

\section{The OӨaakiiwaki (Sauk) and Meskwaki (Fox) (Sturtevant, 1978)}

The OӨaakiiwaki and Meskwaki are two distinctive tribal entities that during the $19^{\text {th }}$ century the United States government blended together. The two groups had been longstanding allies before a splinter group of the Meskwaki returned to their ancestral homelands in Iowa after being displaced to Kansas. Both groups have a long history of attacks by Iroquoian communities, which pushed them farther west, away from their traditional homeland in Michigan, Wisconsin, and Illinois and into Iowa and eventually into Missouri. The Meskwaki had a turbulent history with the French, often attacking their posts in Detroit and in Chequamegon. They were also fierce rivals of the Dakota and Anishinaabe and were not keen on the French expanding their fur trade networks that far westward. The French, in turn, decided the best course of action to address this problem was to attempt genocide of the Meskwaki to completely eliminate them as a threat. Their alliance with the OOaakiiwaki brought about peace, and the French issued a general pardon for both groups; the Meskwaki eventually returned to their lands in Wisconsin. Eventually though, the alliance between the OӨaakiiwaki and Meskwaki soured as reservation conditions, epidemics, and issues with treaties and annuities led to them parting ways.

The OOaakiiwaki and Meskwaki subsisted off agriculture, farming maize, beans and squash on small farming plots on the outskirts of their villages. The women would tend to the farms, while the men would hunt deer, small game and occasionally buffalo. They also foraged for a variety of berries, fruit, honey and other nuts and roots. 


\section{Ancient Cultural Traditions (Sturtevant, 1978)}

Ancient cultural traditions within South Dakota are varied as there is significant portions of time depth. The earliest of these, would be the Paleoindian tradition, which begins around 13,000 B.C. and ends around 8,000 B.C. These groups were highly mobile hunter-gatherers who heavily emphasized big game hunting, primarily going after megafauna. These groups are rare to find in the archaeological record but are often categorized based off of large lanceolate projectile points.

The Paleo period was followed by the Archaic, in which the archaic is represented by three major components. The early, middle, and late archaic. The early archaic, which dates to 8,000 B.C.-6500 B.C. were hunter-gatherers who focused on big game, similar to the paleo however most megafauna by this point had disappeared so they hunted mainly larger game animals such as bison, deer, and elk. These groups were highly mobile, although stayed within certain geographic regions. The Middle Archaic, which dates between 6500 B.C. - 3,000 B.C. began seeing the early beginnings of agriculture, and it is in within this period that copper production begins in the Great Lakes Region. The Late Archaic period begins around 3,000 B.C. and Ends around 1,000 B.C. and it is during this period in which agriculture begins to shift northwards from Mesoamerica and maize agriculture begins shifting northward as well. Early and Middle archaic sites are slightly more common than earlier paleo sites, however since they are still nomadic, the sites are scattered. It was during the Late Archaic that more permanent settlements became the standard within the Upper Midwest.

The Woodland period, which began at the end of the late archaic begins around 1,000 B.C. and continued on until 1,000 A.D. It was during this period in which pottery became a lot more common and would spread across the country. Towards the end of the Woodland period is 
when the shift from Spears and atlatls to bows and arrows took place. It was also during this time period in which the Eastern Agricultural Complex was developed, and horticulture became more common and frequent. It is also during this time frame in which permanent settlements and earthworks began marking the landscapes.

\section{The Middle Missouri (Sturtevant, 1978)}

The Middle Missouri tradition is a semisedentary, horticultural, Mississippian phase cultural tradition that exploited river floodplains for crops and grasslands for hunting. People lived in villages, a stark contrast to the nomadic lifestyles to the Northeast and Northwest during the same time period. It first appeared in the region around 900 A.D.-1,000 A.D.

The Middle Missouri consisted of villages along the Missouri River from southeastern South Dakota to West Central North Dakota. The origins of the Middle Missouri are unknown; however, because origin dates for the different periods are so close, technologies and subsistence patterns appear to have been so well developed that they only required minor adaptation to the new environment. Three subunits of the Middle Missouri include the Mill Creek of Iowa, Cambria in Minnesota, and Great Oasis in South Dakota. It is further subdivided temporally into the Initial (A.D. 1000 to 1300), Extended (A.D. 1200 to 1400), and Terminal (A.D. 1400 to $1550)$.

Characteristics of Middle Missouri include settlement in semipermanent villages that are often fortified and consist of rectangular houses that are located near major streams. The villages were fortified by ditches and vertical post palisades. The villages were built on high terraces that were safe from flooding and overlook the floodplain. Occasionally, villages were in defensible positions on bluffs or high points, but always overlooked a valley. 
Archaeological evidence of subsistence during this period indicates a focus on horticulture, hunting, and gathering. Maize, beans, squash, and sunflowers were grown in household gardens. Animal bones found at Middle Missouri sites include bison, elk, deer, antelope, domesticated dogs, and birds.

\section{The Coalescent Tradition (Sturtevant, 1978)}

The Coalescent Tradition is another key archaeological component found in the Dakota region. Two main time periods for the Coalescent are the Initial, which dates to A.D. 1300-1600, and the Extended, which dates to A.D. 1450-1650. In comparison to the Middle Missouri, the Coalescent has more characteristics in common with material practices in the Central plains, which could indicate an influx of people from that region who brought with them new cultural practices.

The Initial component appears in the central and eastern parts of the plains by A.D. 1300 . This shift in practices and perhaps populations may have been due to climatic shifts around the $14^{\text {th }}$ and $15^{\text {th }}$ centuries, when the Great Plains region became a much more hospitable area agriculture. People of this component practiced a mix of hunting and farming, built small hamlets and the occasional isolated homestead. They cultivated maize, beans, squash, gourds, sunflowers, and tobacco while hunting buffalo, deer, antelope, and some smaller game. One of the main features of the Initial Coalescent is a mixing of their earthen lodges with the defensive fortifications that resemble those of the Middle Missouri. The fortifications may have been a direct result of warfare in the region and postdate the initial building of the villages.

The Extended Coalescent is characterized by the expansion of occupation areas and a decrease in fortifications. The fortifications maintained on the Northern and Southern frontiers seem to be more of an homage to previous practices than for actual fortification purposes. In the 
Extended Coalescent intertribal warfare had seen a significant decrease and this meant that the need for fortifications had disappeared and it was not as important. The north remained fortified; in the south, they let it lapse. Population dispersal and the eventual lack of fortifications during this time indicates that the Extended Coalescent may have spurred the Terminal Middle Missouri. It is possible that migration was a retreat to their cultural relatives in North Dakota. In the next few chapters, I discuss the theory behind many of the trends within archaeology, as well as some decolonization theory and action anthropology theory. After that, I discuss the methodology of how I approach the cultural resource management reports, discussing the processes in which I utilized to identify problematic language, innate biases along with other potential issues with the research. After that, the CRM reports are listed based off of state, and lastly in that same section I have my collaborative projects that are used as a comparative sample. Lastly, I go into the discussion portion, and talk about the findings of the reports, along with some new interpretations based off the same data. But first, we need to segue into the theoretical framework to discuss some of the anthropological and archaeological theory that build our frame of reference while discussing the reports. 


\section{CHAPTER II: THEORETICAL FRAMEWORK}

Theory plays an important role in academia and within archaeology. Theory lays out a groundwork of ideas and methodologies that allow the researcher to follow as a form of guidance within their interpretations. However, these theories and ideologies can shift and change, and it also means that it is important to discuss. In regards to the reports and examples that I have in this research, it is important to understand the theoretical framework in which the researchers had utilized.

\section{Theoretical Approaches of CRM Examples}

The Cultural resource management examples, due to their variety in date ranges also vary in the types of theory they researchers employ.

One of the first, and arguably most prominent examples represented in the reports is that of Culture Historical approach. In this approach, the archaeologists' focuses heavily on defining the historical societies into distinctive ethnic and cultural groups based on their material culture. This was mostly prominent during the first half of the $20^{\text {th }}$ century, when archaeology was focused on identifying and classifying the different cultural groups represented in the data. It is often considered to be the first main theoretical approach within archaeology.

This was later followed by Processual archaeology, which emphasizes being more scientific than anything else. The processual approach to archaeology is one that dominated Cultural Resource Management reports, as they were not in the business of making assumptions or interpretations of the data, instead their job was just to report the facts and that was it. This becomes an issue when assigning significance as, you must make some level of interpretation to 
accurate do so. This was where "information" potential, mentioned by King (2004) really became the main method to assigning significance, based off lack of prior knowledge of a specific group or region.

The Last methodology that is employed, and only used in a handful of approaches is that of Post-Processualism. Post-processualism was a direct reaction to processualist thinking, where the artifacts and the materials that are being excavated do hold some intrinsic value, and should be treated as such. It is through this theoretical framework that many archaeologists attempt to assign religious or ritual value to materials that were excavated.

\section{Theoretical Approaches for This Study}

The Approach that will be taken for this study will be one of indigenous importance. I utilize the framework set forth by Kurt Lewin and Action Anthropology in which it is research, with a purpose. The purpose being that of community benefit and changing the power structure that had been in place in the field for a long period of time. This is coupled with indigenous archaeology and collaborative archaeology which work to bring indigenous voices in to the research, and works to decolonize the field and bring outside voices and perspectives in to the mix. This further becomes more important when discussing the ancestors of these descendant communities, who in turn hold a vested interest in the results of the reports.

\section{Action Anthropology Theory}

This call for change in CRM is a consequence of the theoretical approach of "action anthropology." Originally pioneered by Kurt Lewin (1948), this approach focuses on work to generate knowledge that is "valid and vital to the well-being of individuals, communities and for the promotion of larger-scale democratic chance" (Nesper, 2011). The breakdown of barriers among academics and Indigenous communities has resulted in a democratization of knowledge 
that has seen notable increases in publication in recent years. Instead of just studying the tribal groups, academics are now working with them (Mihesuah, 1998). The main idea behind this partnership is that it can have mutually beneficial impacts: non-Indigenous academics are able to conduct better, more rigorous research and tribal groups are no longer just the subject of research, but instead participants in the construction of knowledge.

An example of action anthropology comes from the Cherokee heartland and working with the Cherokee to preserve sacred sites (Steere, 2017). By interacting with and talking to local Cherokee tribal members, archaeologists were able to locate a number of mound sites that had previously been thought to have been lost. Steere's (2017) project can serve as a model for future collaboration. Because of the inventory of mound sites, the Tribal Historic Preservation Office (THPO) can now use this information for future projects, especially ones that require consultation. It also works beyond the THPO; because these sites are now inventoried and known, archaeologists were able to make the argument that they are significant and deserve preservation into the foreseeable future.

In an example from Indiana, action anthropology helped both to preserve a site and prevent future development of a dam. In this situation, two different sites were observed. One was considered public heritage, and the report discussed how the site had been developed for tourism, which upset members of the tribe in the way it was used as a tourist attraction without consultation or interaction with them. But on the flip side, the other site was preserved because of the amount of public outcry that was spearheaded by tribal members. They were able to drum up enough support and contest the development using a grassroots campaign. In both examples, working with tribal partners enabled both researchers and the public to gain a deeper understanding of the importance of these sites and to understand that it is more than just physical 
remains but rather a piece of their culture. (Kryder-Reid and Zimmerman, 2018). My research works to incorporate action-anthropology by democratizing and opening the contract world of archaeology to outside perspectives. As many of these reports are produced in "grey" literature, which is not publicly available, it works as a gatekeeper to many communities accessing the information available. (Roth, 2010)

\section{Indigenous Critique}

Indigenous evaluations of academic research critique the status quo. For example, DeLoria and Mihesuah (1998) argue that non-Indigenous perspectives will often skew the results and work against Indigenous communities that they intend to understand. Non-Indigenous perspectives may overtly or by implication view Indigenous peoples as unable to conduct proper research and as a consequence are not doing enough to encourage more Indigenous academic research. Indigenous critiques also highlight a point that many Indigenous communities do not want to be the subject of extensive research without any meaningful gain. In this case, a gain is an overall benefit to the community that will have long-lasting positive effects.

Many Indigenous groups feel that archaeology is a permanent, extractive exercise in which non-Indigenous archaeologists conduct the research, the crews pack up their backs, take the artifacts and leave, never to return. Not only is this process insulting because of the lack of communication and consideration of Indigenous perspectives, the published reports and findings offer no benefit to the community. Many communities now withhold permission to conduct archaeological research unless the proposers articulate ways that the research can benefit the community. Such benefits can be something as simple as investigating community-related research questions, such identifying the locations of historic burials without disturbing them (Atalay, 2012). This thesis ties into this critique as with academic research that is conducted with 
tribal nations, CRM projects are necessary to be conducted and this research offers a new perspective to incorporate indigenous perspectives and ideologies into the reports.

\section{Indigenous Archaeology}

Collaboration between academics and Indigenous communities is not new by any means, having originated in the medical field back in the 1980s (Israel et al., 2001). However, within archaeology it has become increasingly more common, to the point that the trend suggests that it will eventually become the norm. Archaeologists across the world have been opening their projects to local communities to come collaborate and participate in the research and digs and while local communities have also been bringing archaeologists to conduct community research projects. (Atalay, 2012). Or, especially in the case of CRM firms, have begun following federal Native American Graves Protection and Repatriation Act (1990) legislation that mandates collaboration with Indigenous communities with regard to the presence of burials, human remains, and objects of cultural patrimony.

Despite this federal law and mandate, a series of issues still exists within the field that make collaboration difficult. One such issue is that of cultural affiliation. This issue was brought to a head with the recovery of Kennewick Man/The Ancient One (Bruning, 2006)). The remains were so old that non- Indigenous researchers argued that no reasonable cultural affiliation could be made, thus collaboration and repatriation were difficult and contested. Instead of working with the tribal groups claiming affiliation, state and federal judges originally allowed research to be conducted against the will of these groups. It was not until a series of legal challenges that this policy began to shift and opened avenues of collaboration. (Bruning, 2006). This policy change in the case of Kennewick Man/The Ancient One led to the five descendant groups (the Confederated Tribes of the Colville Reservation, the Confederated Tribes and Bands of the 
Yakama nation, the Nez Perce Tribe, the Confederated Tribes of the Umatilla Reservation, and the Wanapum Band of Priest Rapids) working together to make sure the remains were properly repatriated and subsequently reburied at an agreed upon location.

Altogether, action anthropology in concert with critical Indigenous awareness foregrounds consciousness of socio-cultural impact of research activities. Most, if not all Indigenous communities have experienced multiple levels of historic trauma relating to so-called "gifts" such as blankets, but infected with smallpox (Patterson, Runge, 2002), or food rations that may stave off hunger, but lead to severe health problems (Milburn, 2004). Within Indigenous communities, navigating both social and cultural impact is constantly negotiated among Indigenous members themselves and with the world around them. My thesis works to bring indigenous perspectives and ideologies into the field of cultural resources management, allowing for a higher level of collaboration between archaeologists conducting these reports, and the descendant communities that feel the direct impacts of the results.

\section{Decolonizing Theory}

Community Based Participatory Research (CBPR) is an anthropological approach specifically geared towards archaeological work that would work to bring under-represented descendant communities and enable them to not only participate but to become a part of the research that is being conducted. Even beyond just becoming a part of the research, CBPR also enables the members of the community to take control and ownership over a project, and in examples given by Sonya Atalay (2012), to reconnect with their shared past and offer up additional insight to the project.

This idea of power and control is one that is common among collaborative writings. In a community based participatory research (CBPR) project, the idea of power should be negotiated 
and agreed upon by both sides. The less power the archaeologist has the better (Atalay, 2012). In these situations, it should not be up to the archaeologist to make the determination of how to proceed beyond using their knowledge of and experience in excavating. This is one of the reasons that having non-Native archaeologists and academics making the determination of significance is innately flawed, as it is devoid of proper representation. Community perspectives and ideologies may vary from what the researcher believes or thinks. Whether this dichotomy is real or fabricated by a person in power must be evaluated, but the trend moving forward is that consultation and collaboration will be of benefit to all.

The idea of power and control from those doing the writings can be traced back to the contact period when early colonial writers would utilize racially biased language to create and perpetuate a system of racialized stratified classes of workers. These positions would be based entirely off of race, and the lower the class, the worse the job would be. The racialized job positions, those that were based off race, were maintained by English settlers in the Upper Midwest region who used this idea of mixed race or Indian blood as a way to argue that their maple sugar was not as "clean" or as "fine" as those made by the full-blooded French.

\section{Midwestern Examples of Collaborative Archaeology}

Archaeological work in the Northern Great Lakes Region has not been the most extensively researched compared to other regions of the US, however, a series of substantial projects have worked with local Indigenous communities. One example is that of a Maple Sugar camp in the Upper Peninsula of Michigan. In this project, archaeologists look at Maple Sugar camps that were occupied during the mid- $18^{\text {th }}$ century and $19^{\text {th }}$ century (Franzen et al, 2018). The authors focus not only on the archaeology, but also on the idea of racism, racialization, and creolization of the inhabitants of this region. They fight heavily against the use of racist language 
in prior reports, even going as far as arguing against the usage of such terms by the inhabitants. Within this region, French marriages produced families; the authors argue against the use of métis, or mixed race, as a form of identity. Instead, they argue that the people of these sites probably identified by clan affiliation, geographic location, or even profession.

In Wisconsin, a series of collaborative projects have taken place along the southern shore of Lake Superior, one of which is the Chequamegon Bay Archaeological Survey, which searched for historically documented Odawa and Wendat-Tionnantate village (Walder and Creese 2018). The survey of this region produced no direct results; however, this negative finding could be due to high levels of deforestation, erosion, lake-level rise, and heavy channel aggradation and sedimentation in the region (Walder and Creese 2018). Because of this project, a subsequent collaborative effort with the Red Cliff Band of Lake Superior Chippewa (Anishinaabe) began in the Frog Bay Tribal National Park (Walder and Creese 2018) This Red Cliff Band project located multiple different complexes dating from the Early Archaic to the Terminal Woodland and into the contact period (Cheli, 2020).

This research aims to be an example of collaborative community-based projects. This project began as a series of personal communications between Edith Leoso the Tribal Historic Preservation Officer of the Bad River Band of Lake Superior Chippewa and me, as an on-going collaborative project looking to decolonize archaeological practices. I took it to the next level by not only including the discussions I had regarding the Ojibwe of the Lake Superior region, but also incorporated aspects of the American Indian Movement and the teachings of both Sonya Atalay and Vine De Loria Jr, to build a more holistic approach to indigenous perspectives. Community based participatory research offers a renewed perspective for academic research and 
potential to help cultural resource management archaeologists improve interpretations of significance in the crucial criteria of Section 106 of the National Historic Preservation Act.

Archaeologists from across the world have been opening their archaeological projects for local communities to collaborate or have begun following federal Native American Graves Protection and Repatriation Act (1990) legislation that mandates collaboration with Indigenous descendant communities when burials are involved. However, in the Northern Great Lakes region where numerous tribal bands still reside, collaboration is barely beginning to happen, as referenced earlier, much of the collaboration has happened in Minnesota and a little in Michigan and Wisconsin, but only in a few specific cases. There has been no application of Indigenous cultural values when re-evaluating old cultural resources management reports that have indicated low to no significance of sites. My research shows that these published findings do not represent Indigenous cultural values but instead can offer an example of how indigenous values can influence or potentially add to the types of significance that can be reported. 


\section{CHAPTER III: METHODOLOGY}

The reports selected for this thesis were based off of report availability at Illinois State University's Department of Sociology and Anthropology. Beyond that, the reports were selected based off of geographic region, focusing on the Upper Midwest of the United States. The reports were also purposefully selected to have a variety of dates ranging pre-National Historic Preservation Act, to modern day to show a shift in processes and perspectives within cultural resources management from inception to current day.

\section{Evaluation Methods}

The best way to re-evaluate CRM projects is to utilize an array of methodologies to understand the issues at hand. The first method is to decolonize the language of the reports. The second is to take this newly decolonized language and collaborate with the peoples who you are studying. By including their perspectives, you can implement a more holistic and appropriate approach towards understanding and evaluating significance of archaeological sites. The collaborative approach that could be the utmost value to both the archaeologist and Indigenous community is contacting and interviewing Indigenous descendant communities for their perspective on effective and respectful research methods, their knowledge about a region as well as items recovered during research. Consultation as part of the research process has been gaining a significant amount of traction in recent years, but has not always been fully utilized (Atalay, 2012). The benefit of consultation and these perspectives are innumerable and could offer unique tribal insight to the project at hand. The archaeologist conducting the research may not be aware of what could be important to tribal members, while from their own perspective they may consider those same observations unimportant. I consulted with Edith Leoso, the Tribal Historic Preservation Officer for Bad River band of Lake Superior Chippewa initially when conceiving 
the idea of this thesis, who offered suggestions for pathways that should be explored when incorporating indigenous ideals into my research. Her suggestion, to include origin stories as a starting point for assessing significance from a tribal perspective was the catalyst for interpretations within this thesis. (Personal communication)

When considering the interpretations and reinterpretations of significance, I had to interpret the authors' emphasis of what was the most important. Some of the reports I analyze explicitly stated what made a site significant or what would qualify the site to be considered potentially eligible for the National Register of Historic Places. In the rest of the reports, I had to interpret statements of importance as indicators of ratings of significance. To keep assumptions to a minimum, I focused heavily on the primary aspects of the reports that the author regarded important enough to discuss and to analyze in depth. Johnson (2006) describes this as the order of the facts, in which he describes that for data to be implemented into theory it needs to be done through an order of the facts, and the stricter and more stringent they are, the less accommodating they can be. Their emphasis of these elements suggested importance because of their in-depth focus on said topics.

\section{Content Analysis}

I identified problematic and racist language by looking for terminology that is no longer socially acceptable as a way to refer to Indigenous communities. Another method to detect racist language is evaluating the context and the notions; this can be as simple as language that maintains or imposes a power dynamic. Tuck and Yang (2012) provided a model for this study's method of content analysis. They showed that historic accounts from French explorers and English settlers use terms such as "Indian" "white" and "half-breed". 
This analysis is done by first recognizing colonialist language in work done centered on Indigenous populations. Colonialist language includes usage of the term "Indian" as opposed to proper tribal affiliation or can go as far as to name Indigenous peoples as "savages" or "halfbreeds" (Franzen, Martin, Drake, 2018). When present, this language actively colonizes and creates biases in the research data because it continues trends of dehumanization that inherently influences thought by using incorrect terms (such as savages or Indians instead of Indigenous or official tribal names). Because of these negative effects, I assessed whether archaeological reports and publications included racist language usage as part of interpreting results. Because the perspectives indicated by this language are so skewed, the archaeologist using them cannot make an unbiased determination of significance. My goal is to encourage an unbiased determination to consider an accurate, holistic, and inclusive series of factors to assess national register eligibility.

\section{Re-Contextualization of Archaeological Data}

In this section, I recontextualize the archaeological data by looking at the evidence presented in the reports by the authors, and then taking indigenous critiques of academics in the past and re-evaluating and re-interpreting the data.

I firstly looked at areas in which the authors took a specific interest in, looking at the areas in which they focused the basis of their attention and information on. I then looked at any utilization of biased language or any inherently biased perspectives in the ways in which they gathered their results. I then look indigenous perspectives on both origin stories and their critiques of how academics never took their perspectives into account and used that as my vehicle for reinterpretation. I utilized ethnographic accounts of origin stories as the basis for my knowledge of indigenous oral traditions, in an effort to both preserve oral traditions that may be 
told from indigenous storytellers but also utilizing information that is not restricted knowledge to the general public. This re-evaluation is done out of respect for the indigenous communities being discussed, but also to show how their perspectives on landscapes may vary from those of the academics. This ties into tribal significance of the project regions.

\section{Assessing Tribal Significance of Project Regions}

The methodology in which I assess and interpret archaeological information from a tribal perspective is by looking at origin stories from each of the tribal nations represented in the reports, looking information of importance within the origin stories, and assessing how it would be translated to archaeological sites. I also utilize tribal knowledge and medicines to make the argument of mobile cultural properties, mainly regarding medicinal plants that are sacred by the tribes and as such hold a higher level of significance. I then look at the local impacts of the reports, looking for any sort of desecration of the landscape, effects on the ecosystem and longterm effects on the ecology of the regions discussed due to their importance.

\section{Oral Traditions}

Storytelling amongst tribal communities is of utmost importance. Community members often carefully select who gets to become a storyteller and carry on the tradition of learning and reciting the histories to future generations. In recent times, that emphasis has only grown. Concerns for cultural and linguistic preservation inspire many groups to do everything they can to prevent cultural loss. Storytelling also is a way to document historic events without transcribing them into texts. This issue of recording the past brings up one major point: one would not write a history of a group without first consulting that group, as it would be viewed as an incomplete perspective on the topic. Why is it that academics discount these oral traditions on the grounds that only written histories hold intrinsic value? The issue lies in that they are based 
on Indigenous storytelling and that because these groups have no written documentation or ability to transcribe the stories that they do not hold the same value. Oral histories that have been transcribed from European sources are still held in high regard, an example of this would be Homer's Iliad.

Indigenous stories counter what a written report states, for example, the tales passed from generation to generation of the 1862 conflict that forced out most Očhéthi Šakówin people from Minnesota. Atrocities the United States military committed included forcing an elderly Dakota woman to her death off a bridge because she could no longer maintain the speed demanded by the troops (Mihesuah and Wilson 1998). This story does not appear in any documented history, but instead was passed down from mother to daughter. Her great-granddaughter, Isabel Roberts or Maza Okiye Win then passed the story on to her daughter, and her daughters' daughter until it was written down.

Storytelling also maintains and shares a considerable amount of medical and traditional cultural knowledge. These stories depict certain elements of plant life or medicines and are often intrinsically linked to the lands in which they are told. For the Anishinaabe, wild rice specifically holds cultural importance as it was the sign and indicator of the lands in which they were meant to migrate too. Even more linked, are the stories and tales of medicines that help cure ailments and work to teach future shamans about the values of local plant life. These stories are linked to the research by both analyzing the content of the oral histories based on their content but also their implied meanings. The content itself is used as a vehicle to transcribe thoughts and ideas throughout history as a form of expression and as a form of record keeping there was no form of written language for much of their history. Secondly, the stories serve as a vehicle for ideas and metaphors to convey meaning and purpose to events and people in the past and in the present. 
Oral traditions have for a long time been discounted as not being accurate, but instead the methodology in which they convey the main points is through a story which can serve as a memory aiding device. The use of storytelling plays a key role in identifying and understanding importance of origin stories. Many of the origin stories mentioned in this research were originally oral histories that were passed down through the usage of storytelling until they were transcribed and published. There are some oral histories that I do not have privilege to access or know, and as such they are not mentioned below.

\section{Local Impacts}

I evaluate the consequences of each report based off modern aerial imaging, comparing to the original site notes looking for site destruction or degradation due to development, vandalism, erosion or any such event that would prevent preservation for the long term. The site maps that are located below (figures 1, 2 and 3) which were compared with imagining located in Google Maps. While some of the sites do not face immediate destruction, many of the reports listed below discuss potential threats that could affect long-term preservation.

The Methodology described above lays out the foundations of what will be the analysis portion when looking at the case studies. Within these case studies, I compare what the author emphasizes is important, how they approach looking at the sites, along with any sort of utilization of racially biased language to interpret their perspective when assessing significance. Even further, I then compare indigenous perspectives on both research and significance and use that as a theoretical framework when looking at the reports. I utilize common knowledge and information of indigenous origin stories as the basis of significance based off cultural values. 


\section{CHAPTER IV: CASE STUDIES}

I organized my evaluation of cultural resource management reports geographically: the Northern Great Lakes and Great Plains region, then further subdivided by individual state. I assess the content of each report for: (1) consultation procedures; (2) the archaeological determination of significance; (3) tribal values of significance of the archaeological evidence; (4) local, continuing impacts of archaeological decision making. These reports constitute a wide array of different types of CRM reports and span different time periods, ranging from the 1930s to the 2010s. This wide variety of reports allows for a thorough investigation into the processes and procedures that archaeologists took when investigating their archaeological research. The point of analyzing these reports is to detect whether any consultation with the tribal groups occurred, and if so, in what way did stakeholders contribute? Further, if the report does not include any level of collaboration with tribal groups, how might the interpretation of significance change if they had? Finally, the assessment of the current condition of each area points out the long-term consequences of those findings of significance. Overall, these case studies show a strong correlation between a Eurocentric frame of reference and the researchers being conducted. It should be noted that if any outside consultation happened, it was not noted within these reports and as such is subject to critique. 


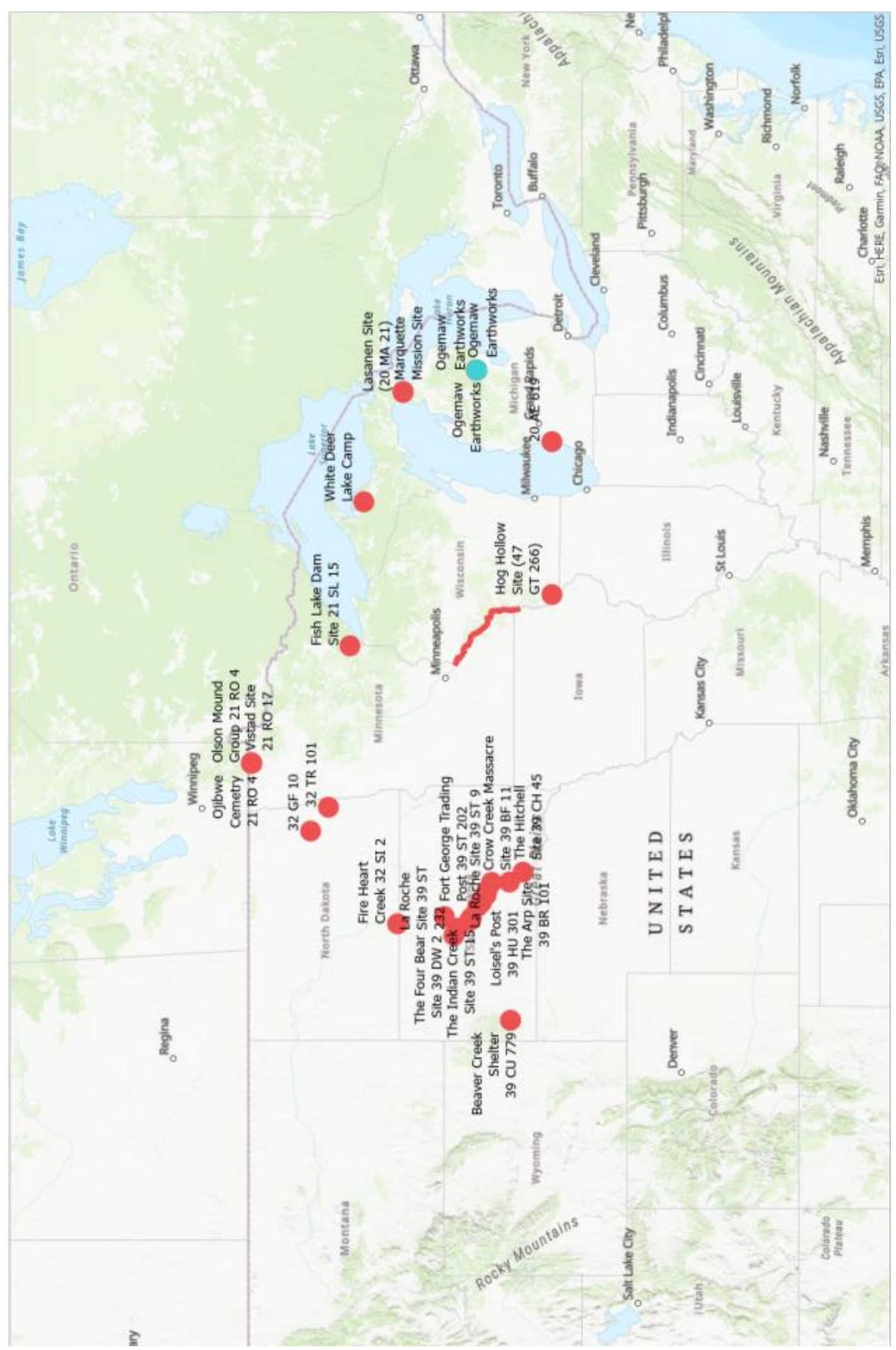

Figure 1 Overview Map 


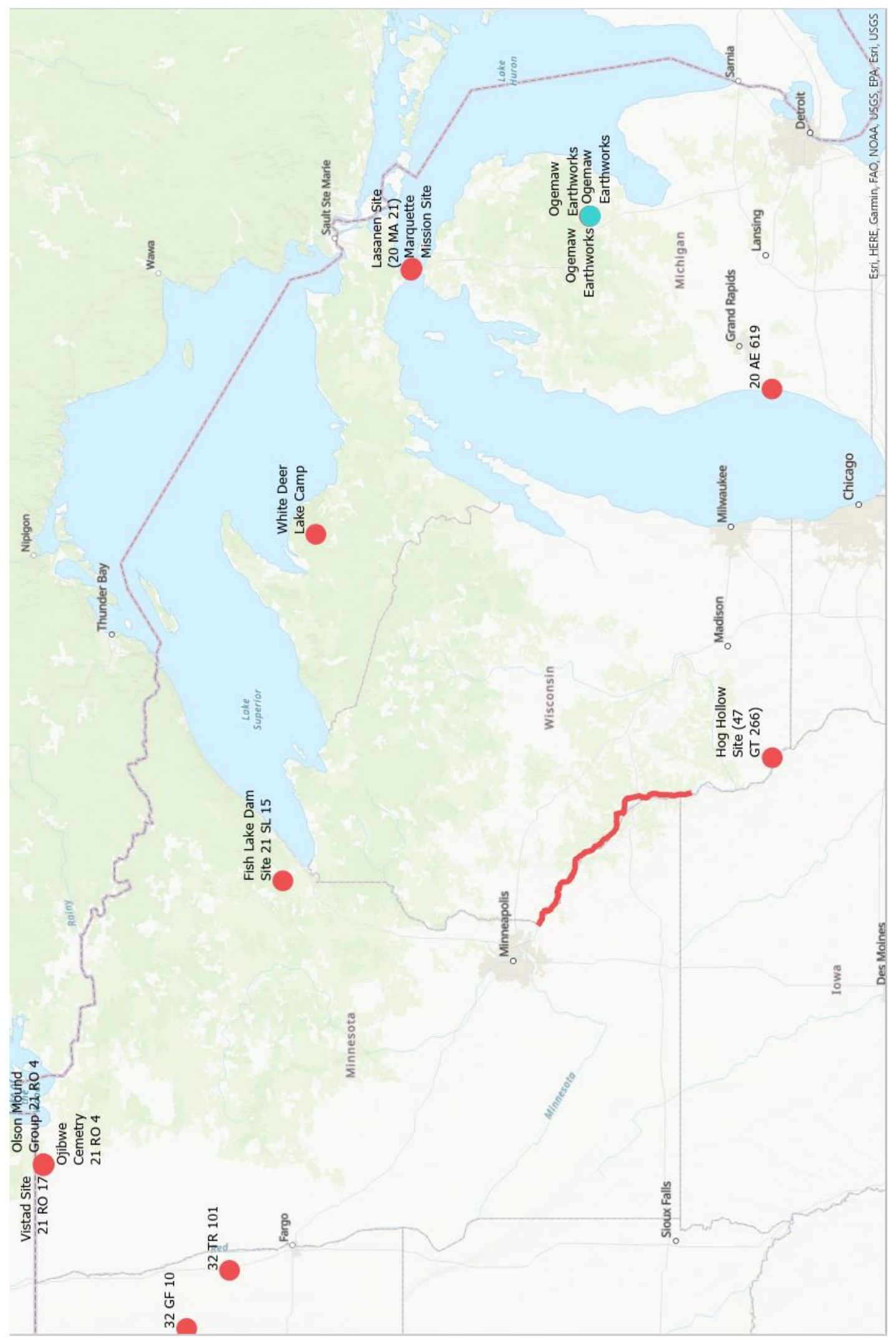

Figure 2 Map of the Great Lakes Region (Michigan, Minnesota, and Wisconsin) 


\section{Michigan}

There are 7 reports from Michigan, ranging from sites on the Upper Peninsula to an overview of Michigan Archaeology, and finishing with two sites near the coastal zone of Michigan. I talk about Michigan to begin, as it is the furthest East state within the scope of this thesis research, and because it is the first state when looking at the Smithsonian trinomial identifiers. Figure 2. Shows the extended boundaries of the sites in Michigan, along with giving a general overview of all the sites in the Great Lakes Region.

1. The Distribution and Abundance of Archaeological Sites in the Coastal Zone of Michigan (Peebles and Black 1976)

This report is an anthology of reports concerning coastal sites along the Great Lakes shorelines of Michigan. The compilation includes a number of sites due to their proximity to the coast.

\section{Consultation Procedures}

Neither the individual site reports nor the anthology summaries state what kind of consultation efforts took place. Consultation in the context of cultural resource management during the 1970s was strictly limited to consulting other agencies and groups who had a vested interest in the project and very seldom would include non-academic or non-agency voices.

\section{Criteria in the Reports for Determining Archaeological Significance}

The basis for significance within this report is purely based off of geographic location. They do list a number of type of sites, whether it is a habitation site, burial ground, village site, or quarry. This gives a good list for the types of archaeological sites that have been studied, although there are certain regions within the report that have no archaeological work completed, or it has been a significant amount of time since the work had been completed.

\section{Tribal Significance of Project Regions}


The report focus on the shorelines immediately calls to mind the Anishinaabe people, who settled in the Northern Parts of the Great Lakes, especially the northern peninsula and northern coast lines of mainland Michigan. They place great importance in this proximity to the shoreline because the Anishinaabe's origin story focuses on the presence of wild rice, manoomin, which needs wetlands to grow: "the Ojibwe people have frequently cited Manoomin (Wild Rice, Zizania Palustris L.) as the guide during their migration to the Great Lakes region as they searched for their prophesized land where food grows on water" (Katanski, 2017). The Anishinaabe highly value these coastal regions and thus would recognize a high possibility for a site to be located there.

The report mentioned the devastation of European settlement for Indigenous populations, however they do not assign a specific cultural component or a time period when the greatest destruction took place.

\section{Local Impacts}

The report does not focus on local impacts of the sites or whether they were at risk of destruction or not. Coastal sites are at risk of rising lake levels, erosion, and vandalism, as recreational activities can cause destruction to archaeological sites. The sites discussed were reference with Google Maps to view levels of signs of coastal erosion.

2. Phase II Completion Report for Conference on Michigan Archaeology (Mueller et

$$
\text { Al, 1980-1984) }
$$

\section{Consultation Procedures}

Most of the consultation discussed in this report came from the section, "Comments on the Archaeology of Indigenous Cultures of Michigan," in which they emphasize the need to have variability when conducting anthropological research. Variability provides differing orientations 
for the generation and testing of hypothetical models. The authors emphasize that culture is abstract concepts that enable it to be replicated in a consistent matter, and that by having this structure it can be organized into stratigraphic layers that can also include high level abstractions such as symbolic meanings. This emphasis relies heavily on cultural historical approach to archaeology with a bit of processualism mixed in. These two theories add a scientific approach to a cultural problem. The approach does eventually taper into post-processualism with using those consistent organized methods to higher level abstractions, however culture is not always consistent nor easily replicated. This approach is further compounded; they continue that everything is interrelated, and that some of the interactions can be manifested in the manufacture, use, and discard of cultural items. This is the post processualist coming out, added a layer of agency within the manufacturing process. Mueller (1984) stated that epigenetics can evaluate political or genealogical differences in mixed populations, although genetic studies can be problematic, especially since the case of Kennewick man.

\section{Criteria in the Reports for Determining Archaeological Significance}

The criteria for determining significance within this anthology of archaeological works varied by chapter. The main focus for many of the chapters is European colonial settlement in the region primarily because of historic documentation of the sites and tribal groups of the region. Different chapter authors make note of the importance of acculturation and that the invasion of Europeans to the region reaped untold horrors for the Indigenous populations. This stress is further emphasized because of the lack of knowledge of some details about ancient Michigan history, which they stressed were topics needing additional research (Mueller et Al, 1980-1984). 


\section{Tribal Significance of Project Regions}

The report discusses the Anishinaabe entry to the Western portion of the Upper Peninsula, emphasizing their emphasis of fish, wild rice (manoomin), and maple sugar. The report also notes how historic period Native American sites in this region receive next to no attention, with the exception of a burial reported to be eroding out of the riverbank near the mouth of the Presque Isle River.

In the Eastern Upper Peninsula, the indigenous communities still hold the same values described just above, as they hold higher significance in Manoomin and in Maple Sugar. The author of the report, Mueller questions how Indigenous communities are currently dealing with the long-term effects of acculturation, especially since all the fur trade has since stopped.

The Ethnographies of tribal groups, the Wendat and Ojibwe place a lot of value in the landscape and the local ecology of the plant life. The food is one of the most important aspects of the landscape and it is reflected as such.

There was a Wyandot burial and village in Detroit in southeastern Michigan. Burials for the Wyandot tended to be a significant event that was followed by a feast and would be a multiday event that would have seen visitors from other nearby tribes come visit for the feast.

In the Kalamazoo basin they identified cultural associations to Algonkian people, potentially the Potawatomi and Miami. This would have been directly within their ancestral homelands where they hold significance on the landscapes and the nearby water systems.

Numerous burial mounds attributed to Hopewell cultures or at least resemble them were noted in the research area. This would indicate that not only was there a belief instilled that lead to the creation of the burial mounds, but it also shows an importance and reverence for the dead, especially after carful interment. 
The most extensive mention of Indigenous communities is within the "Comments of the Archaeology of Indigenous cultures of Michigan" section in which they give an example of a French informant that gave pertinent information and details as to the indigenous cultures and their boundaries within the lands of Michigan. Local Indigenous groups however claim that the boundaries and names that were given were not accurate, nor names they called themselves; instead they were exonyms.

\section{Local Impacts}

This compilation of reports describes a variety of causes of destruction of the sites noted in the studies; details of each region are summarized below. The archaeological work being conducted within the report and in modern days works to mitigate the effects of sites that are at risk of destruction. Whether it is by looting and vandalism or by site development, the archaeologists work to preserve the archaeological materials as quickly as possible.

In the Western Upper Peninsula, the biggest threats to archaeological sites are collectors, developers, and loggers, who will plunder sites for their own gain. In the Eastern Portion of the Upper Peninsula, the biggest damage of sites is done by heavy logging equipment as well as collectors of old bottles and tools who rob the sites of important information. In Northern Michigan, a few of the impacts include private development, road, and highway constructions, with the last having had the most severe impact so far.

In the Northeastern area of the Lower Peninsula, numerous Late Woodland sites along the AuSable River may have destroyed by the construction of five electric generators and flooded pond areas. In the Transitional Zone of West-Central portion of the Southern Peninsula, the areas of high potential for damage are roadways, but can include areas of recreation such as watercourses or shorelines. Construction at these locations, trails, and parking areas can lead to 
heavy erosion and damage. The second kind of impact is urban expansion, such as the construction of an airport in Manistee that destroyed a large Woodland site. Not all is negative though; Michigan issued an executive order that requires compliance of private land modification, and further acts incur penalties such as fines and incarceration for anyone destroying burial mounds.

In the Saginaw valley, collectors are common, and every sand knoll has a little cultural material. Many of these sand knolls have been sold to commercial enterprises. In the Lower Grand River Basin, historic trading posts have been identified and excavated when they were threatened by development. The author recommended the monitoring of gas, sewer, and basement excavations as a part of a continued effort to preserve remains of early contact between Indigenous communities and European settlers.

In Southwestern Michigan, in the Kalamazoo Basin, potential threats to sites in this area are looting, private land development, collectors and soil erosion that takes place closer to the Kalamazoo River. The report author suggests that excavations should quickly follow survey work because the degree of funding and threats to the sites can affect the data recovered. In Southeastern Michigan, a few threats to sites were noted in the report. One incident was the destruction by the French of a painted petroglyph. They thought it was idolatrous because Native Americans traveled there to make offerings to it. Secondly, the city of Detroit is located within the region, and the development of the city can pose significant issues due to urban growth and revitalization. 


\section{Report on Indian Earthworks in Ogemaw County (Dustin 1932)}

\section{Consultation Procedures}

The report serves as an introduction to the mounds of Ogemaw County, Michigan. This is one of the first explorations into the earthworks and attempt to begin to catalog, measure, and take an inventory of the mounds and associated the cultural materials. This report was an inventory of the location of the earthworks instead of the usual salvage or mitigation project.

As was standard for the time, the author partnered with an educational institute, the Cranbrook Institute of Science, and set out to investigate the reported mounds. Also usual at this time, no further consultation beyond contacting locals who may have some insight into the location of these earthworks was undertaken.

\section{Criteria for Determining Archaeological Significance in the Reports}

The significance of the earthworks was not directly stated, however the author mentioned a few important pieces of information. Primarily, the (correct) assumption was that the mounds may have been contemporaneous with the Hopewell earthworks in Ohio, as they shared very similar characteristics.

Secondly, the author also mentioned (with some level of veneration) how each of the earthworks were built in highly strategic locations, usually on a hill or bluff and near waterways. He kept referring to them as "strategic" as a way to reinforce how significant the mound are and that it something beyond convenience informed their location; they were purposefully selected locations.

\section{Tribal Significance of Project Region}

The author recognized that the locations of the mounds are within the historic homelands of the Algonquian people, and that it could have potentially been the Sacs or Chippewa 
(Anishinaabe/Ojibwe) people who inhabited these lands. This region is one of the first locations the Chippewa (Anishinaabe/Ojibwe) had settled once they had begun their great migration further west, this was the first stop after Ontario they had landed. The Sac had occupied the lands before Ojibwe migration. The problem in his language was his use of "primitive" to describe the people who built the earthworks. He refers to them as primitive frequently, but still showed a great deal of respect for them beyond the utilization of biased language.

\section{Local Impacts}

Because of the widely recognized value of the large earthworks, the sites were not in danger of being permanently destroyed, but many of them are located in cultivated fields that were plowed and harvested, which contributes to erosion. The sites took some damage because of plowing and farming, but they were not flattened or destroyed by a dam project.

4. Cultural Resources and Land Use History Background Report on an Approximately 300- Acre Parcel Located in Saugatuck Township in Allegan County, Michigan (McGowan and Walz, 2017)

\section{Consultation Procedures}

This report was an initial step towards consultation on the project. The need for the report was due to a lawyer for a development firm completing Section 106 compliance on a redevelopment project for housing and a marina. As a part of Section 106 compliance, this project served as a basis for assessing possibility of archaeological sites both recent and ancient. As such, it is primarily just background research, so no further consultation took place, even with regard to Indigenous settlement of the region or any legacy settlers in the area.

Criteria for Determining Archaeological Significance in the Reports 
The areas considered significant for this project were identified on the basis of previously completed archaeological work on the town of Singapore within the project area. This settlement was one of the first settler colonial towns in this region and considered to be a rival of Chicago or Milwaukee. It started as a lumber town until the natural resources began diminishing. The area was eventually abandoned or resettled as the nearby town of Saugatuck.

On the other side of the waterway, was an Indigenous village that also had numerous burials located there. The boundaries had never been tested, and this site along with a neighboring sunken schooner The Condor were considered to be potentially eligible for the national register but were never petitioned to be.

\section{Tribal Significance of the Project Region}

The land is situated on the Miami tribes' ancestral homelands. The area of the project is within an zone considered to have high potential for ancient sites because it is located few meters inland from the lakeshore and in close proximity to the inland natural marina that connects to the lake and forms a breakwater. European settlers did not begin to settle in the land until the early $19^{\text {th }}$ century; known historic documentation attest to Indigenous villages all along Lake Michigan's shoreline (McGowan and Walz, 2017). Albeit later arrivals, the Anishinaabe settled the land after being forced out of their homelands back east and eventually lived on this side of the lake and further along the Great Lakes. This region therefore holds high significance to them as water is seen as a significant resource, especially with the presence of manoomin.

\section{Local Impacts}

This report was a preliminary effort to assess the potential for cultural properties to be located within the project area. The author writing the report recommended that further Phase I testing be done, given the location of the Indigenous village and burial located just across the 
waterway, the proximity of the historic Singapore village, and the nature of the site as an area that of sand deposition, which would tend to bury sites. The general lack of ground disturbing activities within the project region led the archaeologist to believe a high potential exists for archaeological materials within the boundaries of the project region.

5. A History of the McCormick Family's Use of White Deer Lake Camp (Karamanski et al, 1980)

\section{Consultation Procedures}

As part of this project, the author conducted firsthand interviews with locals who had taken part in the creation of the camp, had visited, or had some other association with the camp. Absolutely zero mentions occurred of Indigenous communities nearby or any of the research that had been conducted prior to construction.

Criteria for Determining Archaeological Significance in the Reports

The significance of this site was determined by the authors to be its direct association with the McCormick family, particularly and how they utilized the space both as a northern Michigan retreat for family outings and vacations and as a venue for their business and to have meetings there.

\section{Tribal Significance of Project Region}

The value of the project region has to do with its geographic location in the Upper Peninsula, an area that was continuously visited and inhabited since the Last Glacial Maximum. This region is known for its copper production beginning in the Middle Archaic and continuing on into modern times (Lankton, 2010). The Anishinaabe people used this land as their final stopping point in their origin story. They followed the water until they found where food grew on water; in every waterway in this region wild rice, manoomin, grows in abundance. There was 
most definitely manoomin in the area where the camp was created, including in the lake that it sat on.

\section{Local Impacts}

The camp was maintained for 21 years after the last time Gordon McCormick visited the site in 1947. He maintained a staff and had the local superintendent continue his traditions of purchasing gifts for the crew despite his absence. After McCormick died in 1967, the site fell into disrepair.

\section{Archaeological Investigation of the Marquette Mission Site (Stone 1971)}

\section{Consultation Procedures}

The location of the site is within the boundaries of Lake Superior in St. Ignace. The archaeologist conducting this research had been in contact with religious leaders of the Jesuit church that remains in St. Ignace along with members of the local community and government. Despite the fact it was a contact era site and that without witnessed cohabitation between Indigenous communities and personnel of the mission, no Indigenous communities appear to have been contacted or consulted as part of the research.

\section{The Criteria for Determining Archaeological Significance the Reports}

Authors argued that the significance of this site lies its status of being the first mission of Marquette and the first established religious site in this region of the Great Lakes. It also is significant because it is one of the earliest of these missions as well.

\section{Tribal Significance of Project Region}

Tribal significance lays both in the geographic region of this site but also, in the longterm effects after the fact. The mission was one of the first steps of deculturization by the French, and one of the first steps to do that was to introduce religion. The site also was a location for 
cohabitation between 1660 and 1720, and as such was a location where a lot of indigenous culture was lost. Much of the religious and spiritual beliefs of indigenous communities nearby began to shift and change as the European influence actively worked to convert them.

\section{Local Impacts}

The site still exists, although two separate excavations have taken their toll on the site. The excavations were prompted by local Jesuit community, whose members wanted to know the location of the first mission. The excavation crew was provided by local municipal works companies and personnel.

7. A Historic Burial Locality in Mackinac County Michigan 20 MA 21 (Cleland and Buckmaster 1971)

\section{Consultation Procedures}

This report documents no evidence of consultation with local communities or Indigenous communities nearby. The only background information provided was that of a previous archaeological investigation.

\section{Criteria for Determining Archaeological Significance in the Reports}

Significance for this report has to do with the religious character of the findings. Not only does the mission play a big role in the acculturation of the local indigenous populations, but it also potentially demarcated the shift in mortuary practices amongst the tribal communities in the region.

Historic documentation describes a feast of the dead that was often practiced by Iroquoian people. The mass burial found may be evidence of one of the last instances of this type of mortuary practice after the arrival of the European Christians who made it their mission to attempt to change religious practices and beliefs of the local populations. 


\section{Tribal Significance of Project Regions}

The land that the site sits on are the tribal lands of the Anishinaabe during the period of settlement for Europeans. The local Marquette Mission site was established nearby to convert people to Christianity and served as a stopping point for fur traders, as it was a good place to meet with both local mission personnel and the tribal members they were working with.

The mission served not only the Anishinaabe, but also Wendat, Ottawa, and Potawatomi. The burials located at the Lasanen site (20MA21) were not considered by the archaeologist to be an ossuary. Compared to Iroquois burial practices, where the burial numbers were usually over 500 burials at a time, the number of remains was much less. Instead, these remains may be evidence of a Wendat Feast of the Dead, which was documented by the Jesuits. The results of this project may be evidence for one of the final practices of this style of burial.

\section{Local Impacts}

The Lasanen Site lay near the shores of Lake Superior and is not too far from St. Ignace and the Marquette Mission site. The site had previously been impacted at the turn of the century by the construction of railroad tracks on the top layers of the site, although the cultural materials were in a lower layer. Burials were not affected by the construction of the railroad.

\section{Minnesota}

The next state that is discussed is Minnesota. In Minnesota there are two case studies that are studied, the Fish Lake Dam along with the Roseau County projects. These are represented in Figure 3, as they are the second smaller sample size in this research. It is also the second state, when using the Smithsonian Trinomial system as the $21^{\text {st }}$ state, immediately after Michigan. 
1. Archaeological Excavation at the Fish Lake Dam Site: Year 2000 (Mulholland 2000)

\section{Consultation Procedures}

The project began at the request of Minnesota Power because they wanted to know what sites are located on the land and consequently offer continuous support of excavations long after the CRM project ended. After the CRM project had wrapped up, the research involved almost 5,000 hours of labor volunteered by local community members. However, as seems to be the case with most reports, no indigenous community representation was present, nor consulted on this project.

\section{Criteria for Determining Archaeological Significance in the Reports}

The significance of this site was found to be its ability to address a general lack of knowledge of this region of Minnesota. The Fish Lake Dam site is a multicomponent, extensive habitation site that includes everything from Paleoindian, Archaic, and Woodland phases. An entire sequence of cultures is represented, along with identifiable aspects of specific occupations. This influx of information is invaluable for understanding the settlement patterns and resource utilization of most of prehistory and offers insight as to how and when people utilized these types of locations.

\section{Tribal Significance of Project Regions}

The Anishinaabe, who settled much of this land, placed an emphasized the importance of settlement near water. The Fish Lake Dam site is no different. While no dam existed in prehistoric times, the location near waterways and the sheer number of waterways offer insight about why they likely consider this land to be of special importance. 


\section{Local Impacts}

The site is located near the Fish Lake Dam and its associated reservoir. In the fall of 1995, the St. Louis County Department of Public Works was repairing and replacing the Fish Lake Dam Road when they unknowingly bulldozed into the northern edge of the site. A subsequent Phase I survey was initiated as a result. They also wanted to redesign the boat launch areas because it posed a traffic hazard for recreational boaters when they had to cross the road back and forth numerous times. Due to the location of the roadbed, site destruction was considered unavoidable, so a phase III mitigation took place on the hilltop. The site had been cut into due to construction of the new roadway that cut through the center of the site, along with the new parking lot that had been constructed.

2. Cultural Resources Investigation of three Archaeological Sites along the Roseau Flood control Project: Roseau County, Minnesota 21 RO 15, 21 RO 17 (Ketcherside 1982)

\section{Consultation Procedures}

The consultation for this project involved the Army Corps of Engineers reaching out to the University of North Dakota to conduct excavations of the sites. No communication or consultation appears to have occurred as part of the discussion of the historic Anishinaabe burial grounds, nor did any sort of information regarding descendants of people who may be buried there appear in the report.

\section{Criteria for Determining Archaeological Significance in the Reports}

The basis for determining significance within this report was attributed to the nature of the sites. The two areas suspected of burials, the known Anishinaabe cemetery, and the possibility of burial mounds at the Olson Mound Group led researchers to determine that these areas are significant and as such should be avoided in the project. 
The third site, the Vistad site, was not deemed to be significant due to the small amounts of cultural deposits as well as the site being limited to the plow zone within a cultivated field. Additional low significance areas included areas disturbed by activity associated with a brick plant in the adjacent wooded area near the site.

\section{Tribal Significance of Project Regions}

Of the three sites studied, two are of utmost importance to tribal members. The first of which is an Anishinaabe Cemetery, which is also associated with a historic Chippewa (Anishinaabe) village that was forcibly abandoned in 1897.

As for the mound group, two mounds were identified as well as a large depression. They initially did not locate any bodies, and therefore felt it was appropriate to shovel test the mound. A historic account suggests that the mounds may be recent and the result of an accident regarding property boundaries involving a house constructed outside of property lines. It is possible that the house was constructed on the burial mounds, and the burials lie below $90 \mathrm{~cm}$ below the surface.

\section{Local Impacts}

The report was contracted by the U.S. Army Corps of Engineers because of their plans to channel and eventually dredge the river in an effort to help control flooding that occurs two to ten times every hundred years. The Corps ended up modifying their plans to avoid the Anishinaabe cemetery and the Olson Mound group, but the Vistad site was not avoided. 


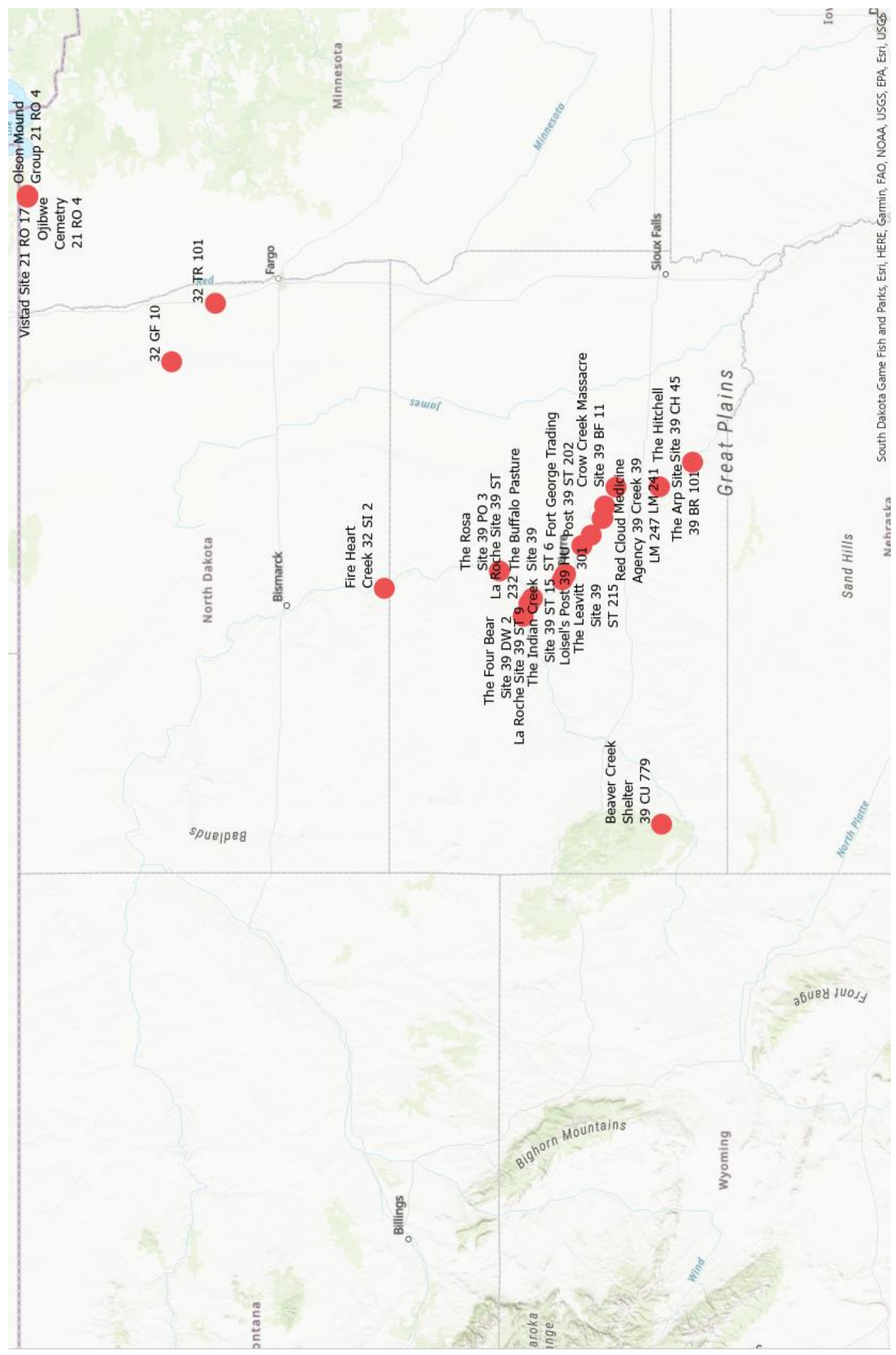

Figure 3 Great Plains Overview 


\section{North Dakota}

North Dakota has 2 sites that have been investigated for this research, the Fire Heart Creek Site and the Goose River Basin sites. These sites are represented on Figure 3, as the three dots above the cluster of South Dakota Sites. North Dakota is next on this list as was previously mentioned, the states are listed based off their Smithsonian Trinomial system, with North Dakota being the $32^{\text {nd }}$ on that list.

1. The Fire Heart Creek Site 32 SI 2 (Caldwell et Al., 1966)

\section{Consultation Procedures}

A couple of collaborative partners participated in this project, mainly the Smithsonian Institute along, the National Park Service, and the North Dakota Historical Society. They worked together to begin the process of excavating the site, which is located at the upper boundaries of the Oahe reservoir. The site is on the west bank of the Missouri River on the Standing Rock Indian Reservation. A very brief mention in the introduction about the Standing Rock Indian Agency was that they supplied drinking water and opened the Indian school for showers. No further mention appears of any additional tribal communications with regard to the excavations of the site. (Caldwell, 1966)

\section{Criteria for Determining Archaeological Significance in the Reports}

As happens in many reports of this era, the focal point of studying the Indigenous cultures of the site is in relation to documents from Lewis and Clark's expedition. Researchers relied upon the expedition field notes and journals, allowing archaeologists to reconstruct the routes that the expedition took. The combination of this documentation and the location of the Fire Heart Creek site led the investigators to conclude that the site is one of those visited by Lewis and Clark. It is one of the only known villages on the east bank of the river, whilst most 
other sites that the expedition visited were on the western bank of the river. The charted course and distances covered in the expedition documentation indicates that the village that the expedition visited was three miles upstream.

To make matters far more interesting, it was during their visit to the village that the explorers made note of several bright white lodges on the hill above the town. By talking with the tribal members of the Sahnish, Lewis and Clark learned that it was the Cheyenne, with more in tow, who were visiting the village at nearly the same time. When describing the Cheyenne Chief's lodge, Clark made note that it was constructed of 20 dressed buffalo skins in the same form as the Očhéthi Šakówin and "other nations" (Ronda 2002, Chapter 2)

\section{Tribal Significance of Project Regions}

The Fire Heart Creek site is located on tribal lands, on the Standing Rock Indian Reservation. The significance runs a even deeper, as it began as a proto-Sahnish site, with some Mandan sites also in the region. During the contact era, some shifts occurred in routes of fur traders, who utilized the Missouri as a main travel and trade artery. When the Lewis and Clark expedition came through, they noted Sahnish hunting parties in the vicinity of the site. It was one of the few villages still standing during this period. The Lewis and Clark reports also note that the last of the Mandan and Hidatsa were gathered in five villages nearby. This was a crucial time and place in the history of these communities.

\section{Local Impacts}

The site, like many others in this area, was submerged underneath the water of the Oahe Reservoir when the government built a dam on the Missouri. The hills that were to the rear of the site now form the modern shoreline of the reservoir. The archaeological sites, though investigated, remain submerged to this day. 
2. Cultural Resource Investigation of the Goose River Basin (Nicolai et al, 1978)

\section{Consultation Procedures}

The investigation of the Goose River Basin was a prescreening for archaeological sites within the watershed. This project preceded any archaeological investigations. The report thus is a primarily a historic report that did not involve contact with Indigenous communities or tribal members to consider the likelihood of sites or what ancestral peoples may have been doing in the region.

\section{Criteria for Determining Archaeological Significance in the Reports}

The report discusses the pre-existing establishment of six historic sites that were already included on the national register, including the Andress O. Ness house, the Carl Ben Eielson house, Col. William H. Robinson house, the Mayville Public Library, the Great Northern Railway Depot, and Baldwin's Arcade.

Previous archaeological work was limited, with not many previous excavations or archaeological work in this area, in part due to a small number of projects completed in the region. The report specifically states that the majority of the work conducted in North Dakota has to do with waterway projects such as a dams and backwaters and that not much attention has been paid to the Goose River Basin. The assumption seems to be that this area would be considered high potential to have archaeological sites, villages and burials often occur near waterways. From an archaeological perspective, this region has potential to have both. The authors also argued that the sites within the project region should be considered significant because of the limited sample size; because of the lack of sites, the known ones should be further studied. The lack of pre-existing survey work in the region, coupled with the intensive periods of 
occupation by both indigenous settlers and historic European settlers, indicates a high probability of cultural materials being located here.

\section{Tribal Significance of Project Regions}

The area of the project region has a long history of Indigenous occupation, most recently of the Dakota, who occupied the lands until the mid-1860s. Historically, the land was occupied by the Dakota before they were pushed farther west by the Anishinaabe. The Anishinaabe established permanent settlements as the fur trade began in the region, with their most intensive period of occupation between 1801 and 1808 .

The Dakota occupation of the Goose River Basin was significantly longer and more constant than that of the Anishinaabe. The Goose River Region was claimed by the Yanktonai tribe, the single largest tribe of the Dakota Nation. They occupied this land until the 1860s when a combination of the disappearance of the Bison herds, military campaigns against the tribe and the establishment of Indian Reservations beyond the region caused dispersal.

The region also had a strong Métis presence related to commercial hunting of bison in the region. Between 1840 and 1885, the Métis group carried on hunting campaigns, eventually depleting the bison as a natural resource. Historic accounts of Indigenous people within the project area serves as an indication of long-term occupation of the basin, whether as a permanent settlement or as a seasonal hunting locale remains unknown.

\section{Local Impacts}

Given the high probability of sites within the project region, the author of the report suggested exhaustive physical survey of the region to search for any archaeological sites and sources. The two sites face threats of erosion from the local goose river, and by farmers plowing 
their fields. The archaeologists recommended further, more extensive field reconnaissance before making a further judgement of significance to understand the scale and scope of the two sites.

\section{South Dakota}

South Dakota is the $39^{\text {th }}$ state within the trinomial system and as such will be the next on the study. There are 11 sites represented from South Dakota and have the strongest emphasis within the scope of this research. The reports center around the Missouri River and the Missouri River basin as the area of focus.

1. Big Bend Historic Sites 39 ST 202, 39 LM 241, 39 LM 247, 39 HU 301 (Smith, 1968) Consultation Procedures

During the process of background research for the dam's construction, the principal investigator did primary documentary research looking at notes and historic documents pertaining to both the Lewis and Clark expedition of 1804 and 1806 along with documents mentioning the fur trade locations of this region. They make note of indigenous presence on the land, both historically, stating the Dakota have had exclusive control of the region since the $19^{\text {th }}$ century, and the high number of ancient components found previously conducted research. No direct consultation appears to have taken place for the project, which happened prior to any federal legislation that mandates consultation.

\section{Criteria for Determining Archaeological Significance in the Reports}

The significance discussed in this report is relates entirely to the "settlements by Whites during the initial periods of commercial and governmental relations with the Indians" (Smith, 1968). They focused primarily on the white settlers, with a slight addition mentioning some relationship with the Indigenous folks of the region. Much of the basis of this report's focus with Indigenous tribes is from the documents of fur traders, notably from the Lewis and Clark expedition of 1804 . 


\section{Tribal Significance of Project Regions}

While religious and cultural significance is not fully known for this region, historic sites that would include white settlers are less numerous than ancient sites. During the era before colonial invasion, this portion of the Missouri River valley was occupied by semi-sedentary peoples who lived in earth-lodge villages. The report notes that these villages were fully abandoned prior to the arrival of white fur traders.

By the $19^{\text {th }}$ century however, this area was under exclusive control of the Western branches of the Dakota. By the 1860s, two tribal reservations were established, the Crow Creek and Lower Brule (Smith, 1968). Many of the settlements were on high river terraces which indicates the importance of high settlements near the water. These high river terraces would have had a vantage point above the water, outside of the flood plain and with access to the land beyond the rivers' valley. This not only ties into their origin stories of being near the water, but also allows for quick and easy food harvesting.

\section{Local Impacts}

These sites and their subsequent land reserves nearby were inundated by the creation of the Big Bend and Fort Randall Reservoirs. Both agencies were relocated to higher ground that would not be flooded by the dams' construction.

2. Archaeological Investigations at the Arp Site, 39 BR 101 (Grant and Howard 1961)

\section{Consultation Procedures}

This project began as a survey conducted aboard the Corps of Engineer launch, The Dakota. It was necessary to survey the shoreline due to massive amounts of erosion. At the Arp site, there were significant amounts of cultural debris and extensive amounts of slumping had taken place already. Several collaborations had taken place: firstly, with the United States Corps 
of Engineers, along with the W. H. Over Dakota Museum and the United States National Park Service. However, no Indigenous consultation appears to have occurred during the entire project; it had not been considered necessary or even recommended during this period.

\section{Criteria for Determining Archaeological Significance in the Reports}

The significance of this site was determined based on the degree of the erosion of the site - erosion had already begun to take effect on the terrace where the site was located. There were two cultural components that correlated with two occupation periods dating from 420 A.D. to 810 A.D. and then 1020 A.D to 1160 A.D. Grant (1961) also states that the this site is significant because it demonstrates the transition from a hunter gatherer economy with limited horticulture to a more complex agricultural village life.

\section{Tribal Significance of Project Regions}

The lands in which this excavation took place is within the historic lands of the Dakota people since the $19^{\text {th }}$ century at the very latest. The site's location also falls within the lands discussed in the Big Bend historical sites studies (Smith, 1968), where prior to inundation, two tribal reserves had been established, along with evidence of several ancient tribal villages in the Missouri River Valley. These lands are exceptionally fertile and were home to several ancient components in part due to the location near the river.

\section{Local Impacts}

The impetus for this project was erosion at the Fort Randall Reservoir in which the Arp Site began to erode out of the banks of the side of the reservoir. Due to the expedient creation of the reservoir, many deep buried sites were missed in survey, so the Army Corps of Engineers surveyed the shoreline for any eroding sites. The report recommends a further, full scale excavation to mitigate the effects of erosion and eventual loss to the reservoir. 


\section{Archaeological Studies of the Rosa Site 39 PO 3 (Hurt, 1957)}

\section{Consultation Procedures}

Located within an area that was planned to be beneath the reservoir of the Oahe Dam, the project was conducted as a part of a collaborative effort between the South Dakota Archaeological Commission, the University of South Dakota, and the National Park Service. There was no requirement for consultation of Indigenous communities during this period, and it appears that no consultation took place during this project.

\section{Criteria for Determining Archaeological Significance in the Reports}

The significance of this site relates to its status as a village. The Principal Investigator of this project made three main notes. First, the early occupation component of the site closely resembles that of the Akaska focus, including evidence such as the brief occupation period, minimal amounts of trash, and the presence of Akaska ceramics such as Akaska Tool Impressed and Nordvold Horizontal Incised. Second, the presence of the village was of utmost interest to the archaeologists; they focused much of their energy in excavation of trenches within the village, which they estimate had 30 lodges. What was of special interest to the investigator was the lack of a stockade or moat or other defensive fortifications. Third, the expedition of Lewis and Clark in 1804 notes a village on the other side of the river. This would mean the Rosa Site had been abandoned prior to this time.

\section{Tribal Significance of Project Regions}

The archaeologists who conducted the survey noted, "assignment of the main village of the Rosa Site to any of the historic tribes is hazardous. The relationship between ceramics and tribal units is tenuous" (Hurt, 1957: 29). They do however, describe how the site may have been home to ancestors of the Sahnish, while the other component related to the Mandan. This could 
not be confirmed archaeologically due to the recovery of only one burial. The sahnish would have utilized this landscape for both agricultural purposes and long-term settlement as they practiced trade with other local indigenous groups.

\section{Local Impacts}

The Rosa Site was located in an area that was inundated by the construction of the Oahe Dam. Estimations given in the report indicate that the Rosa Site is located $99 \mathrm{ft}$ beneath the surface of the reservoirs' water level. (Hurt, 1957).

4. Smithsonian Institution River Basin Surveys, The Hitchell Site 39 CH 45 (Johnston, 1967)

\section{Consultation Procedures}

This project was conducted as a result of the creation of the Fort Randall Reservoir in the Missouri River valley. It was a collaborative effort between the Interagency Archaeological and paleontological salvage program and was sponsored and funded by the United States National Park Service, Department of the Interior, and the Smithsonian Institution. They did not mention any current or historic tribal nations in their efforts to determine more information about the site. (Johnston, 1967).

\section{Criteria for Determining Archaeological Significance in the Reports}

The site was deemed significant due to its location within the Missouri River Valley. Along with the vast number of sites in the region, the site contributed to the Middle Missouri Component and the Coalescent traditions as well as possible transitional phases associated with both. Several burials were recovered within the site but archaeologists did not make a cultural determination for them. 


\section{Tribal Significance of Project Regions}

While no association of the archaeological remains with a tribal entity was determined,

the Dakota are historically present on these lands, and earlier, the Sahnish had been in control of this region. Several burial sites were recorded within the Hitchell site and within the boundaries of the reservoir. Burials play a huge role of importance amongst indigenous communities, as it is often associated with returning to the earth and as a location for spirits to visit. Any sort of disturbance to these burials would disturb the spirits that would be associated with the remains.

\section{Local Impacts}

The location of the Hitchell site is within the boundaries of the Fort Randall Reservoir along the Missouri River. This site was inundated by the construction of the Fort Randall dam. The report makes special note to say that they did not have enough funding, time, or personnel to do a complete, extensive survey and that several vastly important sites of both the Middle Missouri and Coalescent traditions were lost as a result.

5. The Archaeology of Beaver Creek Shelter 39 CU 779 (Alex et al, 1991)

\section{Consultation Procedures}

The consultation procedures for this project were of great collaboration. The project site, located within the boundaries of Wind Cave National Park, was excavated as a collaborative effort between several federal and state agencies: the National Park Service, South Dakota School of Mines and Technology, the Black Hills Natural Sciences Field Station, the Northern Hills Chapter of the South Dakota Archaeological Society, the Black Hills Parks and Forests Association, and the state archaeologists for both South Dakota and Iowa. Additional support 
was provided by the South Dakota Archaeological Research Center. Indigenous communities do not appear to have been deeply involved in the project design, implementation, or interpretation.

\section{Criteria for Determining Archaeological Significance in the Reports}

The criteria for determining the Beaver Creek Shelter site as significant involved several factors. Primarily, the site provides an opportunity for studying the relationship between ancient cultural and paleoclimatic events over a 6,000 year time span (Alex et al, 1991). The site also provides a chance to study the relationships between ancient cultural and paleoclimatic changes as occupation of the site and regional climate varied. Furthermore, it provides a unique look into the earliest settlement of the Black Hills throughout the Holocene.

\section{Tribal Significance of Project Regions}

The Black Hills are considered sacred by the Dakota tribes. It is considered an area of great importance to the tribe as the location where they would follow the buffalo herd while performing a series of rituals during the process. This land contains two immeasurably important sacred sites, Bear Butte and Devils' Tower, where they conducted sacred ceremonies and signaled the end of the journey following the buffalo herd. The type of ceremony and which of the two locations they would end up at varied on the time of year and route followed.

\section{Local Impacts}

The Location of the Beaver Creek Shelter site is protected within the Wind Cave National Park and thus is not under any threat of destruction due to construction or erosion. The archaeological remains are within a cave that provides shelter from erosion and may be subject to depositional events that may further protect the site from both looting and erosion. 
6. The Crow Creek Site Massacre 39 BF 11 (Zimmerman, 1981)

\section{Consultation Procedures}

The site was an already known and established archaeological site on the National Register of Historic Places as a National Landmark. During a routine tour conducted by members of the South Dakota Archaeological Society, a staff member broke away from the tour group to assess the effects of erosion on the ends of the fortification ditch. It was at this point he noticed a bone eroding from a cut bank a meter below the surface. Further inspection confirmed that it was a human bone. The South Dakota State Archaeologist Robert Alex then notified the Corps of Engineers - Omaha District, who requested that a University of South Dakota Archaeology Laboratory survey crew remove the skeletal remains and stabilize the banks. The land is located near Fort Thompson on the Crow Creek Očhéthi Šakówin Reservation. The Tribal Council was notified of the action so they could add input on the excavation and reburial.

\section{Criteria for Determining Archaeological Significance in the Reports}

The site had already been considered eligible and subsequently placed on the National Register prior to the discovery of the bodies, however once the bodies were located, the true nature of the site became known. The nature and number of humans remains excavated informed the site's ultimate significance. Several hundred individuals had been killed and mutilated.

\section{Tribal Significance of the Project Regions}

The site was a Proto-Sahnish context, then enemies of the Očhéthi Šakówin. Nevertheless, they were concerned with the consequences of the excavations. They wanted the bodies, removed, studied, and reburied. As tribal customs dictated, that all the bodies had to be excavated and moved together, as they should not be separated even in death. After excavation and study, the bodies were eventually reburied together. 
The author of the report also makes a very strong statement, "the time has come that serious consideration be given to uniform treatment of human skeletal remains discovered on federal property... Federal legislation should be passed so that any time human bones are found on federal property consistent treatment of the bones is ensured" (Zimmerman, 1981).

\section{Local Impacts}

While the site was not slated for immediate demolition, the level of erosion and subsequent looting that took place on the site made the removal of skeletons and stabilization of the banks necessary. A looter had unintentionally undercut the walls of the banks, causing slumping. The positive effects of collaborating with tribal members was strong, as they were able to repatriate the remains for subsequent reburial, which was as the tribe had requested.

Furthermore, members of the tribal council assisted with the excavations; other members of the tribal nation provided nourishment and drinks, along with visiting the site and participating in the research.

7. The La Roche Site 39 ST 9, 39 ST 232 (Hoffman, 1968)

\section{Consultation Procedures}

The consultation procedures of this project were cut and dried. They needed to excavate sites within this region because of the dam construction and subsequent flooding. The project was conducted by the Smithsonian Institute's River Basin Survey project, which worked along the shorelines of rivers that were about to be affected by dams. A common theme for these projects was underfunding and construction often outpacing the ability of the archaeologists and researchers to complete initial investigations.

Criteria for Determining Archaeological Significance in the Reports 
The La Roche Sites were considered significant within the report due to their proximity to the Missouri River, along with an early village component at the Overs' La Roche site. In 1938, the presence of the village was confirmed via aerial photographs. All structures had circular floors of similar design that could have been earthen lodges. The report suggests that they could be predecessors to similar modern structures. The sites also are considered significant due to the great date range of occupation, from 100 A.D. to 1650 A.D.

\section{Tribal Significance of Project Regions}

The presence of both Middle Missouri and Badger components along with their associated date ranges means that the site could be an origin place for the Sahnish and Chahiksichahiks peoples of today. Within the report, the term "aboriginal" is far too common, and the lack of further investigation of potential tribal affiliation leads one to think there was minimal effort placed in understanding the entire picture.

\section{Local Impacts}

This site, along with many others along the Missouri river valley, was subsequently inundated by a reservoir project in 1964 . The site now sits below the current water level of the reservoir. The high bluffs located behind the site are now the modern shoreline of the lake.

8. Archaeological Studies, Four Bear Site 39 DW 2 (Hurt et Al, 1958-1959)

\section{Consultation Procedures}

The site was first located by William H. Over during his archaeological surveys of South Dakota and was selected and noted because of its possibility of being the Sahnish Village seen by Lewis and Clark on October $6^{\text {th }}, 1804$ (Hurt et Al, 1959). The project was a collaborative effort between the South Dakota Archaeological Commission, the W.H. Over Museum of the State University of South Dakota, and the National Park Service as a part of the Missouri Basin 
Project by the Smithsonian Institution in an effort to salvage the site before it was covered by water from the Oahe Reservoir project.

While the report does not include the type of communication or collaboration, it was mentioned that Noralf Nesset, Superintendent of the Cheyenne River Reservation, granted permission for the field crews to utilize the Four Bear Day Schoolhouse as a field headquarters. The site is located within the Cheyenne River Indian Reservation, within the Four Bear district. The Four Bear district is where the site gets its name. The district was named after Chief Joseph Four Bear of the Two Kettle band of Teton Dakota (Hurt et al, 1959).

\section{Criteria for Determining Archaeological Significance in the Reports}

The significance of the site was based on the number of village sites within the Missouri River Basin along with the size of the village. The size of the village inspired a prominent focus, especially during a time and financial crunch for the project. The site, while having numerous houses, also contained a burial ground. The location would have been ideal for a year-round permanent settlement as a farming village during the warmer summer months and a winter village because of the protection it provided. It was also listed as a Sahnish visit based on the accounts of Lewis and Clark, who also noted the permanence of the site, in the wider context of the Sahnish being known for their seasonal hunts.

\section{Tribal Significance of Project Regions}

Tribal significance of the project begins with the location of the site on the Cheyenne River Indian reservation, which means all the work that conducted was on the reservation. Second, it was a village site located in the densely populated Missouri River Basin. Third, both the presence of the village and its burial ground where ancestors lay buried are important to local Indigenous history and culture. The village site played an important role as it served for summer 
and winter residency and food needs. It supplemented the food supply for agriculture in the region, which emphasized the cultivation of Northern Flint Corn that was mixed with a variety from the American Southwest (Hurt et Al, 1959). The village also served as a site where the elderly or young could stay back and look over the fields while the rest of the community went out on seasonal hunts. Bison and other fauna provided necessary food to keep the village going.

\section{Local Impacts}

Despite its location within the boundaries of the reservation, the site still fell victim to the mass infrastructure projects of the mid- $20^{\text {th }}$ century. The Basin along with the site and many others were located beneath the Oahe Reservoir and dam. The site has since been covered in over $100 \mathrm{ft}$ of water, making it truly inaccessible. Of the 37 earthen lodge houses that were identified, only one was fully excavated.

9. South Dakota Archaeology, Journal of South Dakota Archaeology Society, Vol. 2 (Zimmerman et al 1978)

\section{Consultation Procedures}

This journal is composed of eight articles that describe and discuss various aspects of South Dakota's past. One of the articles describes looting and the effects it has on archaeological sites in Iowa was also discussed. In that article, Zimmerman describes how archaeologists contact locals to talk about their experiences and knowledge of a cave site. The rock shelter and cave were subjected to almost 80 years of looting and pothunting. These locals, by describing either their digging techniques or by discussing what they knew, were able to help piece together the rest of the puzzle before the owners of the land eventually contacted an amateur archaeologist. That person informed the state archaeologist about the existence of the site so that it could be further excavated. 
In the case of the Crow Creek Massacre site, members of the South Dakota Archaeological Society were both looters and researchers. Many members admitted to pothunting on the site before a looter and vandal desecrated burials within the site. That destruction led to an immediate action to protect the sites against this more of this kind of behavior.

\section{Criteria for Determining Archaeological Significance in the Reports}

One of the articles describing cultural resource management practices within the Black Hills National Forest discusses the four criteria for the national register. They list these as follows: (1) historic buildings and areas; (2) prehistoric sites; (3) areas of importance to the heritage of living cultural groups; (4) other types of cultural sites and data that have scientific value. The article further explains why these criteria are important, and it boils down to the same reasoning for all four: cultural resources cannot be replaced or renewed if they are destroyed. It is an archaeologist's job to discern as much information and data from these sites as possible before future developments or further looting destroy them.

\section{Tribal Significance of Project Regions}

Tribal significance was not discussed nearly as much in this journal as it probably should have been. One example that they did discuss, although venturing away from the point, was that of the Big Horn Medicine Wheel's use. The author (Park, 1978) describes how Indigenous folklore gives us no clue as to its usage and instead discusses archeoastronomy. They try to demonstrate the usage of the Big Horn Medicine wheel as an astronomical tool to view the stars and solstices. However, the author did not discuss this topic with tribal members who may have sacred knowledge or information about the wheel's usage, but evidently instead opted to come to their own conclusions. The wheel was of great importance to indigenous communities as it was a 
location that was frequented often, both as a vision quest and as a sacred location. This utilization of the site as a religious function, gives a deeper context as to the importance of the location, especially considering that it was utilized heavily both pre-European settlement and post-European settlements. (Liebmann, 2002)

\section{Local Impacts}

Two of the sites mentioned in the issue were under threat of vandalism. Normally, the sites were in the way of developments or of future dam and waterway projects, but in this case the sites are at risk of or have already been vandalized. The two sites, Crow Creek Massacre and the Quandahl rock shelter have experienced instances of looters either bypassing federal legislation willingly or unknowingly looting the site of valuable information that now cannot be studied.

10. Arikara Archaeology: The Bad River Phase 39 ST 6, 39 ST 215, 39 ST 15 (Lehmer and Jones, 1968)

\section{Consultation Procedures}

As is the case for many of the River Basin surveys, this archaeological project resulted from great collaboration among several government offices and facilities. It began as a part of the Interagency Archaeological and Paleontological Salvage Program, sponsored and funded by the National Park Service and the Department of the Interior. A later partner was the Smithsonian Institution, which assisted with planning and programing. The report does not have any evidence of contact, written, or personal communication with any tribal members who may have any information or vested interest in the works being conducted. 


\section{Criteria for Determining Archaeological Significance in the Reports}

One of the main ways the report established significance of the Bad River Phase Sites was through the usage of the journals of Lewis and Clark. They held that as the golden standard for historiographic information about the tribes of the region. The focus was very Eurocentric and pinpointed dates of specific villages if Lewis and Clark mentioned it in their reports. They also brought up a point of European contact with the Indigenous tribal members of the region when they mentioned that the eastern groups who participated in the fur trade tended to have an advantage when it came to intertribal warfare. It was also a point that the introduction of horses to many Plains tribes made migration easier. The specific examples were that the Comanche and Kiowa Apache moved into the plains from the west, while other groups moved in from the east like the Očhéthi Šakówin and Anishinaabe. The other primary reasons for significance include the number of village sites within the project area along with the number of human burials that were present.

\section{Tribal Significance of Project Regions}

The archaeologists conducting the research and eventually writing the report discussed the importance of the site as it pertained to the Sahnish, along with several village sites, burials, and burial cairns. This region was very heavily settled by Indigenous tribes but not by European settlers. Since there was very minimal contact with European settlers in this region, many of the European traits are borrowed or indirectly developed. The Sahnish were a Caddoan speaking group that is linguistically related to the Chahiksichahiks. Many of these village sites were continuously occupied until at least the $18^{\text {th }}$ century, as noted by the Truteau visit of 1795 . A few years later, during the Lewis and Clark expedition, the sites were claimed to have been abandoned. In an entry from September 29, 1804, the expedition reports state that the Sahnish 
Chahiksichahiks had a village five years ago and also record a handful of other abandoned villages along the way.

Nicholas Biddle's notes, which he clarified upon visiting with Clark, state that the Sahnish are colonies of Chahiksichahiks who emigrated from that nation. After the $17^{\text {th }}$ century, the area had several changes that affected the ways of life: mainly, the introduction of the horse, expansion of the fur trade, and epidemics disease such as smallpox.

\section{Local Impacts}

The sites were excavated under threat of destruction from the Oahe dam. Each site was excavated in preparation for the dam's construction, however the remnants of the sites suffered various fates. The Dodd site was dug out and hauled away for dam fill in 1950; 39 ST 216 was destroyed by the contractors' power shovels. The Left Back village, 39 HU 22, is buried under the east end of the Oahe dam. The Phillips Ranch and Leavitt sites were removed during the grading process. The last site, Buffalo Pasture, survived longer than the rest, but inevitably inundated by reservoir waters. Currently, the site now lies more than $100 \mathrm{ft}$ deep under the surface of the water.

\section{The Black Partizan Sites 39 LM 220 (Caldwell 1966)}

\section{Consultation Procedures}

No mentions occur of any sort of consultation with Indigenous communities in the area, however the report does very briefly note that the site is situated about five miles south of the Lower Brule Reservation and is in an area of a fairly high density of sites. The project was conducted as a part of preliminary research of the river valleys before the dam was created. The Black Partizan sites were selected for study because they were deemed to be in the utmost danger of inundation by the backwaters of the dam. This assessment ended up being true. 


\section{Criteria for Determining Archaeological Significance in the Reports}

One of the main methods of determining the significance of these sites was both their location as an area within the backwaters of the dam and their interconnected relationships with a number of neighboring sites. A few sites located within the same region of the Missouri River Valley were noted for sharing similar technologies. This report in particular took a deep look at the typology of the pottery and based many of their interpretation on their research results. The typologies and characteristics of the pottery led the investigator to believe that the site contained two separate, distinguishable cultures. However, with an addition to the report five years after it was originally drafted was that different components were related and that the original author did not see or understand the similarities (Caldwell 1966).

\section{Tribal Significance of Project Regions}

The sites were located in an area of heavy site density along the Missouri River and they are also right next to the reservation of Lower Brule. Minimal mention was made of any modernday tribes beyond that it was near the Lower Brule. They do discuss two ancient traditions, the Coalescent and the Middle Missouri, which may be material evidence of the ancestors to the Sahnish and Chahiksichahiks people of today.

\section{Local Impacts}

While it was considered in an area that was ideal for the backwaters of the Oahe Reservoir project after it was completed, the Black Partizan site was specifically selected for study because it was an ideal location for the backwaters of the dam project. This ended up being true - the area for the dam fully inundated the site. As was noted in this report and many others in the same series, the work was rushed, and it was not a fully comprehensive excavation because they worked on both a limited budget and time frame. 


\section{Wisconsin}

Wisconsin is the $48^{\text {th }}$ state within the Smithsonian trinomial system and as such is the last state to be visited in this research. There are four reports represented here, with two of them being based on the same archaeological site. The Hog Hollow site has the initial site report and a second re-evaluation of the initial report.

1. Great Lakes Archaeological Research Center Report 151 (Overstreet and Van Dyke, 1981)

\section{Consultation Procedures}

This preliminary report is effectively the consultation needed for future developments of this site. This report in particular serves as an inventory or pre-research being conducted within the alluvial deposits around the Portage and Lewiston Levees. Direct contact with Indigenous communities was not indicated in the report.

\section{Criteria for Determining Archaeological Significance in the Reports}

No significance was assessed by the report; instead, they focused on regions along the river that could potentially have significant sites or buried deposits. They conducted interviews with local landowners and collectors, along with conducting some shovel testing and soil probing in the region. They located four new sites within the project boundaries, however they deferred any significance assessment until after a phase II survey had been conducted.

\section{Tribal Significance of Project Regions}

Archaeologists did not evaluate tribal association, but many indigenous groups both recent and ancient have utilized the Wisconsin River valley extensively, both for resources and for travel. They utilized the food resources that the river offered, the chert deposits on the rock 
cut faces of the river, and the river itself as a form of ancient mega-highway to transport goods throughout the region.

\section{Local Impacts}

The purpose of this report was to assess the information potential of bluffs near the river along with ways to prevent and control future erosion. The investigators wanted to search for any sites that could be affected by erosion of the shorelines and to prepare the report for the Corps of Engineers as a form of risk assessment.

2. Additional Material from and Notes on the Hog Hollow Site 47 GT 266 (Lowe, 1986)

\section{Consultation Procedures}

No consultation had previously taken place regarding the Hog Hollow Site. The area had been excavated twice, once by a group of archaeology students from a club from the University of Wisconsin - Platteville and another time by a CRM firm who conducted one test pit excavation (listed below). Despite the extensive amounts of cultural materials excavated and the numerous tribal nations residing nearby, within the state of Wisconsin no communication or consultation had taken place about the site.

\section{Criteria for Determining Archaeological Significance in the Reports}

The site was deemed significant based on the results of previous excavations that identified the extent of the site as well as a multicomponent habitation.

\section{Tribal Significance of Project Regions}

The site was occupied for a very long time, dating as far back as the Middle Archaic, continuing all the way through to the contact period. The site falls within the Mississippi riverway, which was extensively utilized for trade, transit, and subsistence for dozens of tribal nations throughout the ages. Numerous tribal groups traveled up and down the Mississippi River, 
trading copper from the Great Lakes, shell from the Gulf, and pipestone from the Dakotas. The extensive amount of trade along the river is by the source of the raw material for the artifacts and artifact density of the site. Assessing cultural affiliation for site such as this would greatly benefit from consultation to evaluate who may have resided here.

\section{Local Impacts}

In the report the author states that the archaeological site had begun to suffer from extensive erosion from the dam and backwater slough. They estimated that the site would be entirely destroyed in 50 to 75 years. They further recommended that the site should be fully excavated and supported an attempt to stabilize the riverbanks.

3. Historic Sites along the Great River Road (Rusch and Penman 1982)

\section{Consultation Procedures}

The consultation for this project was the evaluation of historic documentation for the parcels of land along the Great River Road. The investigators looked for any indication of historic buildings or residences that still remained along this tract of land. This investigation did not prioritize Indigenous homes of the past or present nor did the report indicate conversations with local Indigenous communities.

\section{Criteria for Determining Archaeological Significance in the Reports}

The basis for significance in this report has to do with the historic nature of many of these properties. The researchers were especially interested in any buildings that would date to the era of the most intensive usage of the Great River Road and did not focus on much beyond that. They briefly mentioned locating over 236 ancient sites, but make no further mention of what those sites were like. 


\section{Tribal Significance of Project Regions}

The report makes numerous references to lands ceded by Indigenous nations, including what they described as a "half-breed tract". This is the only mention of any sort of Indigenous or Métis group in the entirety of the report beyond listing their identification of 236 ancient sites versus the 52 historic sites that the report focuses on. The land in which this project was located is located near the Mississippi river valley which is a major trade route, along with it being the ancestral homelands of the Očhéthi Šakówiy, Their origin story states that humans originated from the land that was pulled up beneath the water, so the lands near the river were venerated as being closer to the creation.

\section{Local Impacts}

Most of the sites surveyed in this region were either still standing or remained in use, with two of them remaining in the family who originally settled there. A number of sites had fallen victim to a farmer's plow, meaning that much of the site had been disturbed by plowing by local farmers and had affected the site's distribution.

4. Great Lakes Archaeological Research Center Report 149 (Overstreet, 1984)

\section{Consultation Procedures}

The archaeologists conducting the research interviewed many people who had previous knowledge of the site. These informants were primarily local residents who were around during the time of the original excavations in the 1940s. However, no mention was made of any attempt to contact any Indigenous communities in Wisconsin or the neighboring states that would be able to contribute valuable information and knowledge regarding importance of the site. The archaeologists make note of over a dozen Indigenous plants and medicines, but make zero 
connection to how Indigenous communities could utilize these resources or why it would make for an appealing place to settle.

\section{Criteria for Determining Archaeological Significance in the Reports}

The site was considered significant for being a part of what they referred to as the "Old Copper Complex" and because of the site's size and scale. The copper artifacts played a huge role in the consideration of the site being significant, a determination further supported by the indication of nearly 500 burials at the site.

Despite these important reasons for a finding of significance, the evaluation was primarily based on evidence for resource exploitation and regional exchange. The presence of copper here dated to the Late Archaic period. The basis of the wide scale trade network ranging from the northern Great Lakes region down the Mississippi River, to other regions of the country such as the American southwest were substances such as copper, galena, and chert. In many of the burials on the site, Gulf Coast marine shell was present.

One of the main factors beyond site degradation that would prevent its listing on the National Register is the lack of features at the site despite the heavy artifact concentrations.

\section{Tribal Significance of Project Regions}

The area is located within the Mississippi river valley and has strong connections to others sites in the region, and well beyond in an extensive network. The indigenous perspectives on this area would have placed a great importance with the landscape in which it is situated. Every tribal group discussed to this point has placed a massive emphasis on water being sacred, as it is believed that many of them originated from beneath the water. The high terrace in which the site sits also holds some importance, as both a defense protection but also as a way to avoid the seasonal flooding that occurs in this part of the basin. 


\section{Local Impacts}

The project area was slated to be developed into a recreational area to include the constrauction of a shower building, a new campsite area, new roadways, a boat landing, amphitheater, picnic area, caretaker's facilities, and playground areas. Despite the area being considered potentially eligible for the national register, effects of erosion, vandalism and site degradation made that eligibility unlikely. Furthermore, the presence of a full-time occupant, the caretaker, would help prevent future vandalism and site degradation.

The site itself was located after a lock and dam construction in Dubuque took place in the mid-1940s. The inundation of the riverbanks caused the terrace suffering from erosion to emerge from the water.

\section{Collaborative Reports}

\section{Archaeological Reports with Indigenous Collaboration}

A few examples of collaborative projects offer comparisons with the CRM studies presented so far. The CRM case study for the Bad River Band of Lake Superior Chippewa of Northern Wisconsin is the 2011 Duluth Archaeology Center investigation of the Northern Shore of Lake Superior. The aim of the project was to take an inventory of archaeological sites along the Northern shore of Lake Superior within the State of Minnesota. Their methodology for this research was to conduct Phase I shovel testing and pedestrian survey. This area of research, referred to as Section 9, is located 80 miles west of Bad River's tribal reservation, although both areas are within ancestral Anishinaabe lands.

\section{Consultation Procedures}

The 2011 Duluth Archaeology Center report made a small note that they requested permission to excavate on tribal property, but that request was denied. No additional consultation 
took place when the survey was conducted. This lack of communication and consultation, while not legally required, provides important insight to the significance that the tribe itself holds of the lands they occupy.

\section{Criteria for Determining Archaeological Significance in the Reports}

The criteria for determining significance as demonstrated in the report (Mulholland et al., 2011: 9) was that they viewed any pre-colonial, pre-contact site to be considered significant due to a lack of prior research in this region. In the report they located six new additional sites along with the originally known 67 other sites within Region 9.

\section{Tribal Significance of Project Regions}

While this project did not directly impact the Anishinaabe, it was a part of their ancestral homelands prior to treaties and splintering of the tribe into smaller bands. The Red Cliff Band of Lake Superior Chippewa had conducted its inventory of archaeological sites within tribal boundaries as a part of the Chequamegon Bay Area Survey conducted by Dr. Heather Walder and Dr. John Creese (Walder and Creese, 2018) and by a graduate student assisting on the projects (Cheli, 2020). In these projects, archaeologists assisted the Red Cliff Band of Lake Superior Chippewa in assessing the number of archaeological sites within their tribal reservation, along with setting up a local tribal depository for any archaeological materials recovered.

\section{Local Impacts}

Evaluation of these cultural resource management reports as well as published academic articles show the frequent use of biased language. Such language can lead to interpretations based on implicitly biased languages, which can be as simple as using the English term for an Indigenous group or for their important medicines. Even the use of "wild rice" instead of Manoomin could be considered an example of implicit bias. The results of the Duluth 
Archaeology Center's project were that the land was not impacted by further developments; instead, the project was conducted to take an inventory of archaeological sites within the geographic region referred to as Region 9 in the reports. No lands were disposed as a result. While this research worked to protect the sites from further development, no consultation seems to have occurred about how the land should be preserved or why it would be of importance to local Indigenous communities.

\section{Anishinaabe (Ojibwe) Examples}

The Anishinaabe people originated on the eastern side of the Northeastern portion of the United States and Canada until colonialism and encroachment from other neighboring tribes made migration one viable option of survival for the Anishinaabe. They subsequently began travelling west as they searched for the land where food grows on water. This land turned out to be the Great Lakes region, especially around Lake Superior. Most of the projects described below occur within areas close to Lake Superior and are either within the local state discussing nearby sister tribes or involve larger swaths of land on the northern shore of Lake Superior.

\section{Example 1}

In Minnesota, a cultural resources project along the Northern Shores of Lake Superior took inventory of numerous sites in Region 9, which includes Carlton, Cook, Lake, and St. Louis counties. Of 67 sites, six new sites were identified that ranged from Paleoindian to Woodland time periods. Most of these sites occurred within $100 \mathrm{~m}$ of water (Mulholland et al. 2011).

\section{Consultation Procedures}

The group conducted the extensive survey covering hundreds of miles of shoreline and sites within the northern shoreline of Lake Superior. Investigators briefly discussed being in contact with the Grand Portage Band of Lake Superior Chippewa, but did not appear to have 
consulted with them about anything beyond asking permission to excavate. It would have been ideal to have asked permission to establish a collaborative project with the Tribal Historic Preservation Office. It is through such steps that Atalay (2012) suggests that collaborative projects begin. Furthermore, they instead handicapped their research capabilities as they strictly looked for material remains of the region. Most archaeologists, especially those in cultural resources management are not aware of criteria for significance of descendant communities, yet it would be learned almost instantly by consulting a member from a band of Anishinaabe people.

\section{Criteria for Determining Archaeological Significance in the Reports}

No ecological impact survey was done to assess how any future developments could impact the plant life near the sites they had located. They also made the determination that any undisturbed pre-colonial contact site would be considered significant due to the low volume of sites in the region.

\section{Tribal Significance of Project Regions}

Of the 67 total sites documented in the report, 40 are located within the $100 \mathrm{~m}$ of the water, aka the "rice zone." Of the 17 sites located beyond $100 \mathrm{~m}$ of water, five are on or near glacial lake shorelines. Two main patterns for all the sites were proximity to water and the typical slope. More sites occurred on smaller slopes, with $51 \%$ of sites having less than a 5\% slope and $22 \%$ of sites with up to a $10 \%$ slope. A substantial number--27\% of sites-occurred on a slope of greater than $10 \%$, but the researchers did not survey areas of lowest potential, which they considered to be extremely steep slopes, areas with a high water table, and a lack of easily accessible water.

The report notes that they located the remains of an Anishinaabe village. The presence of Anishinaabe peoples in the region invokes their view of the significance of their land. 
Anishinaabe origin stories indicate that they originated in the aastern portion of North America and then migrated to the land where "food grows on water." Reliance on this food that grows on water is a celebration of the importance of Manoomin (Wild Rice), an important aspect in the life and culture of the Great Lakes Anishinaabe people. Beyond a basic importance of food that gives life, the Anishinaabe built their entire culture around this vital plant, incorporating it into their medicines and oral traditions. The reliance on Manoomin as a subsistence and medicine underlies the Anishinaabe argument the food holds significance for its cultural and historic value and thus its presence would make an area significant.

Environmental variability played a role in the location of sites, shown by a Paleoindian component on the old glacial shorelines. During the Archaic period, there was a high amount of seasonal variability of Lake Superior's water level, resulting in some areas with more intensive occupation than others. Post glacial rebound and sedimentation of the landscape led to more lakes and tributaries forming. The Woodland phase witnessed the highest density occupation of the region, although not in great numbers. These sites are identified by the occurrence of diagnostic points such as a Snyders Points. Burial mounds and ceramics are rare in this region. Water is vastly important for wild rice, which grows near the shores of freshwater sources. The archaeological results indicate that villages were in close proximity to the wild rice beds. From an Indigenous perspective, this pattern demonstrates their core values of the importance of Manoomin (Katanski, 2017). The emphasis of manoomin goes beyond that of a sustainable food and even further than an origin story; the emphasis invokes the process and ritual of wild rice harvesting, in itself a vehicle for storytelling and oral histories. Anishinaabe scholar Kimberly Blaeser (2013: 253) writes: "rice kernels fall back upon the fall waters, sink slowly again to the soft silt. Stories, too, must seek fruitful grounds, settle, arise again in new 
voice. We only continue by the grace of these spirit acts. Somewhere there is intersection between the motion of stories, the motions of life, and the mobile centers of meaning." The details show how oral histories relate to the wild rice, falling into fertile soils, to be sprung anew in a different light. The stories remain the same, but the voice telling them changes, and they grow and resprout in each new voice.

\section{Local Impacts}

The project was mainly for the purpose of site inventory of Region 9; no developments were planned for this region. They did not further develop the land or region, but instead were searching for archaeological sites to have a knowledge base. In their research, the archaeologists managed to locate four additional sites than what had previously been known, and as a part of the final report made suggestions for future research. The impact for the Grand Portage Band was not mentioned - the report mentions them once, in an offhand way to tell about being denied permission to excavate on the reservation.

\section{Example 2: Crandon Mine}

\section{Consultation Procedures}

In the case of the Sokaogon Anishinaabe, tribal partnerships with academic researchers helped fight against a mining project that would have destroyed the local landscapes (Nesper, 2011).

\section{Criteria for Determining Archaeological Significance in the Reports}

The determination of significance for the Crandon Mine was based on local tribal histories and first-hand accounts of important aspects of their tribal lands. They also made the argument that local medicines were a mobile cultural property. 


\section{Tribal Significance of Project Regions}

The results of the archaeological surveys conducted in this region with collaboration from the Sokaogon Anishinaabe provided a significantly more in-depth analysis of local medicinal plants and landscapes that were previously not studied by Eurocentric archaeologists. The collaboration enabled researchers to view and understand which plants were considered to have held cultural value in the eyes of the local tribal communities. It was through this collaboration as well that tribal Elders were able to express their thoughts of how the landscape holds value for their people.

The Sokaogon also cited socio-cultural impact to argue against the Crandon Mine. They actively worked to shut down the progress of building the mine by arguing that the land itself held significant cultural value. Development of the mine would negatively impact the tribal reservation, which is across the street from the proposed mine construction (Nesper, 2011).

\section{Local Impacts}

The mine project eventually failed after significant protests by the Sokaogon Anishinaabe and the United States Supreme Court stepped in. In their decision, the Supreme court reaffirmed the right of Indigenous tribes to have "treatment as a State" when setting and applying clean air and water standards, which in turn were more restrictive than those of the state. Eventually, the Mole Lake band of Sokaogon Anishinaabe partnered up with the Forest County Potawatomi to purchase the mine site and end development threats for the foreseeable future. The two tribal groups coming together not only to collaborate in fighting a much larger imminent threat and to bring finances together to protect the landscape shows that these ideals are not unique to one single tribe. The beliefs and ideals that surround landscapes is something that many tribal groups 
from across the state and even throughout the country share, and it is something that European descendants may not understand.

Example 3: Medicinal Plants

\section{Consultation Procedures}

When searching for information about medicinal plants, researchers interviewed tribal officials and elders to ask about the importance and location of medicinal or sacred Indigenous plants. Interviews were conducted on three projects specifically. The first was with the Crandon Mine Project, when tribal elders and senior members of the tribe were asked where local medicinal plants were located (Nesper, 2011). Farther north, in the collaborative project conducted by Matson et al. (2021), tribal elders from multiple Indigenous groups were tasked with going throughout the Lake Superior region to find and document known locations of wild rice beds. Lastly, in Erdrich's (2003) report, a significant number of native plants were evaluated for their medicinal purposes and some of their uses.

\section{Criteria for Determining Archaeological Significance in the Reports}

This landscape survey emphasized plant communities. The significance of the plants was based on tribal histories and stories. Important plants include Labrador Tea, Swamp Tea, Makigobug. Snakeroot, Balsam, Ininiwunj (milk weed) Omukikiwidasun (pitcher plant), willow for indigestion and basketmaking, inner bark for headaches, Makibug (sumac) for dysentery, white cedar for coughs. Also important are highbush cranberry, blueberries, juneberries, wild currants, and gooseberries. Winabojobikuk is a treatment for snakebites (Erdrich 2003, 22). Settler colonial perspectives on these plants are profiteering and value in high intensity resource collection. Because of this settler colonial mentality, those seeking to profit from these plants 
tried to take control of the landscape, forcing the Indigenous communities off the land and further abusing the landscape to their own benefit (Tuck and Yang, 2012).

\section{Tribal Significance of Project Regions}

One of the main oral traditions that is passed down amongst Anishinaabe cultures is that of medicines, specifically natural medicines found in the local landscapes. An example from the Sokaogon Anishinaabe is that tribal medicines are considered mobile cultural property, which per Section 106 of the National Historic Preservation Act would be deemed significant.

\section{Local Impacts}

The Crandon mine project ended up faltering as companies looking to begin operation of the mine faced significant resistance from the indigenous community nearby. Eventually, they sold the mine property to the tribe who had partnered with other indigenous nations to allocate enough money to purchase the property. They effectively shut down the mine for any future activities. As for the wild rice in the Lake Superior Region, the wild rice beds that were known have since been protected by local caretakers who aim to keep the wild rice flourishing.

\section{Example 4: Wild Rice Research}

In Minnesota, one group of academics from the University of Minnesota and tribal members from 15 different nations worked together to assess the impact on wild rice harvesting both ecologically and environmentally (Matson et al, 2021). In this case, researchers worked with tribal members to look at the impacts on wild rice harvesting from governmental laws that attempt to revoke tribal treaties protecting the right to harvest as well as ecological impacts such as environment loss. 


\section{Consultation Procedures}

This project was directly in contact with 15 different Indigenous nations and tribal bands, ranging from local ones such as White Earth and Grand Portage to Lac Du Flambeau. The researchers specifically made sure that there was enough representation from each party that has a vested interest in the cultural properties of Wild Rice.

\section{Criteria for Determining Archaeological Significance in the Reports}

The significance of the wild rice was entirely based on Indigenous perspectives. Because it was such a large collaboration among numerous tribal entities, the researchers tried to present diverse Indigenous perspectives in a balanced and accurate way. Each tribal group participated because of their expressed interest and concerns with the universities' practices of genetically modifying the plant life: "we came together with a common goal: to understand the multiple facets of Manoomin through research predicated upon respect for tribal communities and for Manoomin itself" (Matson, et al, 2021: 109).

\section{Tribal Significance of Project Regions}

The White Earth Band of Anishinaabe in Minnesota adopted a tribal law that recognized the intrinsic rights of the wild rice. This legal action resulted from outside pressure such as legal battles about usufructuary rights of off-reservation harvesting, and additional pressures of appropriation in which companies attempted to genetically modify and patent the wild rice (Bouayad, 2020).

\section{Local Impacts}

This partnership in assessing the impacts works not only to find a sustainable solution to keep the wild rice thriving and present, but also to benefit the tribal members through an ability to vocalize their concerns and fears about the degradation of environment (Matson et al. 2021). 
White Earth Anishinaabe now argue for their rights in the face of mounting legal challenges from the Enbridge Line 3 pipeline that involves considerable environmental risk and that could further impact the landscape, and by association, the wild rice.

\section{Discussion of Results}

The results of my analysis of cultural resource management reports are two-fold. Firstly, I discerned the archaeologists' evaluation of significance by their emphasis of what they considered to be important, whether that was by marked emphasis within the report itself or by explicitly stating what they considered to be the most important. A lack of consultation went hand-in-hand with results that focused almost exclusively on a European perspective of Indigenous cultures. This focus showed up in looking at only historical sites that were the result of European settlements in the region or from using historical accounts of ancient people as a lens through which they viewed the archaeological data. The reports that focused on collaboration show the value of having outside input on research and how to build a positive working relationship with descendant communities. While these projects may not be entirely archaeologically focused, they do allow for tribal input and add value for not only the researchers but the communities who will face the longstanding impact of any sort of change to the local landscapes and ecology.

The landscapes that have been researched were continuously inhabited in one form or another for thousands of years. Each tribal nation that occupied the lands held inalienable beliefs that the land held significance and value beyond what archaeological researchers had determined. As a result of this disconnect, many of the landscapes that were investigated were destroyed or altered beyond repair, and much of the archaeological sites surveyed are no longer available to be preserved or researched in the future. 


\section{CHAPTER V: DISCUSSION AND CONCLUSIONS}

I focused on three issues for each of my examples: the language of the report, by searching for any loaded, biased language; two approaches to significance for the findings of the research; and impacts of the results of the study. The re-assessment of site reports reveals the missed opportunities for requesting tribal input and shows how such information could have impacted their site reports, especially by potentially adding mobile cultural property and landscapes to strengthen their arguments of significance.

We can compare these CRM examples to collaborative projects within the region, including projects from Minnesota, Wisconsin, and Michigan to identify crucial differences and similarities in benefits and direct consequences of these projects. The differences between the various reports were the type of consultation that was undertaken; for the collaborative projects it was a key factor in their research, for the CRM work it was an afterthought. Similarly, all the tribal collaborative projects took place within the same geographic region, and all were centered around the Anishinaabe tribes in the region.

Indigenous perspectives on landscapes are fluid, varying from tribe to tribe, however what does not change or shift is the high importance that many indigenous groups place on the landscapes. From the examples I discussed above, each one of the tribal nations that are represented have origin stories that involve how the world was created, and each one incorporates aspects of the natural world as their form of spirituality. The Sahnish, Rųwą́rka·ki, Hidatsa and the Očhéthi Šakówin all have very similar origin stories in which the first creator of mankind lifted the mud from beneath the water and created land and then made agreements with the local fauna as to how to live and survive on the landscapes. For the Anishinaabe, their 
importance of the landscape too revolves around the water, however in their specific case, they believe in a spirit telling them to go to where they find food growing on water. This directive guided them to the Great Lakes, where they discovered manoomin (wild rice) and consequently, following the guidance, settled down nearby. The groups of the study region not only venerate the lands as being important, but also see it as a relationship between themselves and the land, and offered it respect, for it is what provides sustenance to them via the foods they grow or the animals they raise.

This value is one of the areas that authors of the reports fail to understand or emphasize. The landscape from indigenous perspectives is vastly different from that of the settler colonialist mindset in the United States. This mentality of taking the lands because the European settlers would put it to better use or maximize the yield of the land does not adhere to the indigenous mentality of balanced give and take. Not only do the reports lack the wherewithal to understand the importance of these landscapes from the indigenous perspectives, but also they focus mainly on European accounts of the landscape instead of tribal traditions or oral stories of the lands. This problem is further exacerbated by the time the researchers looked at historical accounts. The Eurocentric view was most notable in the examples from North and South Dakota.

\section{North and South Dakota}

In the Dakotas, all but one of the reports dealing with this region had an entire section focused on the expedition of Lewis and Clark. In numerous examples of these explorationfocused assessments, authors directly compared their archaeological results with that of historical accounts of the Lewis and Clark expedition. Not only did the Lewis and Clark expedition miss numerous Sahnish village sites along the Missouri River, but also examples of distances between recorded settlements or locations were inconsistent with the archaeological results. This over 
emphasis of the Lewis and Clark expedition exposed flaws within their journal records and also brushed past some vastly important events within tribal life during the latter parts of the $18^{\text {th }}$ century into the $19^{\text {th }}$ century. The archaeological analysis mentioned a group of Očhéthi Šakówin and Cheyenne visitors to a Sahnish village, but then researchers made zero mention of the trade among these groups and the likelihood of finding diverse cultural materials within the microregion. This directly coincides with the migration and trades between the tribal groups of the Dakotas, primarily the Sahnish and Očhéthi Šakówij. The Sahnish villages noted in 1804 were abandoned due to the increased violence and warfare between the two tribal groups. Evidence of this warfare can be found in the Crow Creek Massacre report, which specifically notes a battle with mutilated warriors (Zimmerman, 1981). Even beyond the reports of graves, a shift in defensive fortification occurred at the Four Bear Site and at the Crow Creek Site massacre; researchers argued that tribal warfare triggered a shift in the use of defensive fortifications. The Sahnish had been heavily defending their entire villages, as they were in the South. As violence and conflict forced them farther north, up the Missouri River Valley, their defenses shifted from protecting the entire village to having the palisades protecting their south edges. This architectural and town plan change coincides with the movement of the Očhéthi Šakówin into the region. While intertribal relationships were tumultuous at first, relations shifted as time went on.

The Fire Creek Site report from North Dakota indicates a Sahnish village; as discussed above, the important story of this time was that both the Cheyenne and Očhéthi Šakówin were visiting the Sahnish; when the Lewis and Clark Expedition came through was only a brief engagement. While trade during the $19^{\text {th }}$ century was a common occurrence, the beginning of the $19^{\text {th }}$ century was a time in which two transhumant groups, the Očhéthi Šakówin and the 
Cheyenne, visited the sedentary, agricultural-oriented Sahnish. They traded bison furs and meats for maize and squash that the Sahnish cultivated. This trade benefited groups because they it was a form of peace and collaborative work. However, it was due to the Očhéthi Šakówin's pressure on the Sahnish that forced them to maintain a year-round sedentary lifestyle instead of their earlier semi-nomadic life of maintaining their village except during their semi-annual buffalo hunting trips. Due to the effects of smallpox and encroachment on the groups, the Hidatsa, Rųwą? ka·ki and Sahnish consolidated their own individual villages and groups to create a more unified triumvirate, an important turning point in the history of these tribes.

Eventually, these sites and their cultural materials were inundated by the construction of large dams and reservoirs. This not only submerged one of the most occupied ancient regions, but also affected the landscape in the long term. All of the North and South Dakota sites discussed in this thesis have been fully submerged and even to this day face degradation, as the water causes mass slumping and erosion to the terraces that the sites once sat on top of.

\section{Michigan}

Reports dealing with Michigan offered the widest scale and view of archaeological resources, including one of the first reports - dating back to the 1930s (Dustin, 1932). In that report, the archaeologist made cultural comparisons of the mounds to the Hopewell mounds in Ohio as well as incorporated ethnographic knowledge that the land is on historic Chippewa (Ojibwe) and Sac lands. Currently, archaeologists hesitate to assign cultural affiliation, especially with older date ranges. The assumption by archaeologists is that the groups have shifted and changed and that contemporaneous tribal nations are in some way disconnected to these ancient groups. Indigenous groups argue the opposite, they make the argument that they are not in fact separate groups from this ancestral tribes, but instead a modern continuation of them. 
The report The Distribution and Abundance of Archaeological Sites in the Coastal Zone of Michigan, a compilation of reports about sites along the coastlines of Michigan, very briefly mentions the devastation of European settlers for Indigenous groups of the region but does not delve much deeper. The report is important because some tribal groups like the Anishinaabe focus much of their energy and resources to be around and near water, because it pertains to their origin story. In contrast, the report Cultural Resources and Land Use History Background Report on an Approximately 300-acre Parcel Located in Saugatuck Township in Allegan County, Michigan focuses on a small parcel of land just past the shoreline of Lake Michigan near a natural water inlet. While this report did not contain any archaeological survey results, its author makes a few assumptions primarily related to the Singapore township. The township was already on the national register. The report refers to archaeological sites found during survey on the opposite shore as support for the assumption that the parcel being studied had a high probability of having a similar archaeological site.

Other Michigan reports offer a wide array of information about ancient Michigan as well as the current state of the field (in the 1980s) for the archaeology of Michigan. This report is important for its inventory of sites and knowledgeas well as author's perspectives on how to improve and move forward. This helpful analysis has the potential for being key in future research, as it offers a starting point.

Once we shift our focus to the Upper Peninsula things get interesting. Everything that is written about the sites up there had a European settler lens - the sites included in these reports are discussed solely from that settler colonial perspective. The main focus was on the Marquette mission, which was vastly important to European settlement of this region. The mission, however, did not operate in a French-only vacuum. The reports fail to mention important aspects 
regarding Indigenous life nearby. The mission site was a hub for many of the local Indigenous populations to congregate both as a way to be involved with the local fur trades based in the region and with the mission site itself, to convert from traditional lifeways to a more EuroChristian lifestyle.

Neither Archaeological Investigation of the Marquette Mission Site nor A Historic Burial Locality in Mackinac County Michigan goes into much depth about the Indigenous populations, beyond a brief mention of the Wendat Feast of the Dead. At the burial locality site, the festival of the dead is an important Wendat tradition in which the deceased from the past 8 to 12 years are moved to a permanent interment. Not only is this a massive oversight that misses an extremely important ceremony of the Wendat, but it also shows that these practices had taken place contemporaneous with the mission site. The missions were a congregational point for Indigenous groups also for economic activity as a place to trade furs and hides for European goods. The sites can be considered significant from an Indigenous perspective as they both are evidence of rituals of the region and their location within Anishinaabe ancestral lands that are along the waterways.

This Eurocentric perspective does not only appear in work at those two sites, but also throughout Michigan. The attention of archaeologists conducting research in other contests has been on European settlers as a way to identify the significance of sites. The survey regarding the 300-acre parcel of land (McGowan and Walz, 2017) focused much of their research and energy on the abandoned village of Singapore buried beneath the sands, yet devoted only minimal attention to an Indigenous village located just across the water inlet. Granted, in that specific example, they had not done survey work adjacent to the village of Singapore, but given the location, the preference for water resources, and the knowledge of the site across the water, the 
areas adjacent to Singapore should have been an area of more significant effort to identify ancient cultural materials that could be present under the dunes.

Interviews and compiling first-hand accounts of sites is also something that researchers are capable of. The case of the McCormick Family's Use of White Deer Lake was a premier example of being able to conduct interviews and take first-hand accounts of the sites into consideration. Despite the age of the encampment, the researchers took down first-hand accounts to supplement their knowledge of the lodge from previous research. Such interviews appear to be something willingly done for European settlements, but not Indigenous ones. As is the case for many of the CRM reports, there was no mention of tribal members or inhabitants nearby, even though the Upper Peninsula is home to the L'Anse reservation. It has been known for a very long time that the Upper Peninsula was a place that was extensively utilized throughout ancient periods as a location for fishing and copper production. The lack of a mention of any of this Indigenous presence and activity in the area shows a level of bias.

\section{Minnesota}

Minnesota archaeological reports all seem to have been relatively the samein that they identify significant archaeological sites within project boundaries but still fall short of incorporating Indigenous perspectives on the project area and findings. Unlike the Dakotas and Michigan, the archaeologists researching Minnesota sites did not favor European settlements yet conducted the work without any Indigenous perspectives or input. Each of the three reports from Minnesota consists of an area of high concern for the local tribes, especially the Anishinaabe who inhabit the region today. The first project, the archaeological inventory within Region 9, the archaeologists note that 40 of the 67 sites located are within $100 \mathrm{~m}$ of water, and all are within drainages and terraces. To their credit, the archaeologists do not attempt to interpret this pattern 
beyond just making note of it. When you consider how important wild rice is to the local tribes, proximity to water makes a significant difference in the interpretation of the site.

Researchers noted an Anishinaabe cemetery and possible mound works located in Roseau County and indicated that they considered both areas to be significant, but they stop just shy of asking the local Indigenous communities about how or why the sites might be important to them. These reports shift the perspective from the previous examples of looking at archaeological sites from a Eurocentric perspective instead to a more balanced analysis, but without incorporating other perspectives and ideals into their interpretation. A more inclusive interpretation would not change the significance of the site, but instead it would introduce a new way to view the site as being significant. The researchers took a different routes than community-based participatory research or Indigenous archaeology, but ended up in the same place.

The last example from Minnesota context is the Fish Lake Dam, in which again the archaeologists conducting the survey say the site is important and should be both studied and preserved moving forward. The multicomponent site, located on the Fish Lake Dam, was significant because it adds additional knowledge of a region of the state that has not been previously studied. Because of this, after the initial CRM report was completed, a volunteer academic project continued to work on the site with the cooperation from the company that owned the dam and the site. Because the researchers found significance in the site based on lack of prior knowledge o the region, along with the integrity of the site and potential for damage, they continued their research. The unique thing about this project is that they utilized local community members and actively invited them to be involved in the project. The aspect of note is that the local community members did not include tribal descendant communities. Even though the project had a public aspect, just not with the groups who previously occupied the site. 
This omission can lead to a problem of both cultural stewardship and heritage conservation. Unfortunately, involving the public and engaging with outside perspectives can still alienate Indigenous parties from even participating.

\section{Wisconsin}

The Wisconsin CRM reports offer a variety of types of CRM reports, including kinds of interpretations and possibilities for making corrections to previous work. Two main reports serve as a standard; beyond that is a risk assessment report and a revisitation of one of the sites mentioned in an earlier report. The issue that Wisconsin has is similar to cases previously mentioned: they focus on European perspectives and activity in the region and not Indigenous cultures that were present. One of the most flagrant examples of such omission is the Great River Road project, where the archaeologists surveyed a large tract of land in hopes of finding evidence of the first European settlers in the region. Hyper-fixation on the European settlement patterns is not terrible on its own, but the report states that they found over 236 ancient, preEuropean invasion sites within the project boundaries, but never mention them again. A clear bias in the goals of the research exist in their singular focus on one, clearly smaller aspect of what research detected.

This problem also occurs in the research of a site near the Mississippi River. The site in question is known from materials recovered, but instead of consulting any descendant communities about the likelihood of a site being located there, they contacted locals who had memories of walking the shoreline, picking up artifacts. These first-hand accounts of the landscape and the artifacts collected should not be discounted, but asking for an Indigenous perspective would have given key details about how they may have settled on the landscape or what would have been of importance to the people who settled there. When reanalyzing the site 
years later, researchers deemed the context to have the potential to be considered eligible for the national register of historic places due to its multicomponents dating from the Middle Archaic to the contact era. However, due to site degradation, erosion, and the utilization of the property as a recreational zone the site has been left off of the national register. The report claims that repurposing the area for recreation and having camping on the location of the site would preserve it from looting and vandalism. This argument appears to have been made without consultation or asking about Indigenous thoughts on the reutilization of the site for recreational purposes.

\section{Collaborative Reports}

The results of my analysis should prompt archaeologists to reconsider their approaches to determination of significance when looking at culturally significant landscapes. Collaborating with Indigenous descendant communities would not only enable archaeologists to have a more holistic approach to their research, but also to recalibrate issues to pay attention to while in the field. Plant life and ecological systems may not be what archaeologists are searching for, but they can help determine the significance of a landscape. The reports that do involve collaboration offer Indigenous communities an opportunity to have a voice when it comes to studying their ancestors. Such collaboration takes some of the points that Atalay (2012) and DeLoria (1992) made about transitioning from Indigenous peoples being the subject of study to becoming the researchers. This divorce of power and introduction of outside perspectives is one of the only true ways you can shift ideologies and work to decolonize the field.

The collaborative projects mentioned give an insight as to how the Anishinaabe were able to take their concerns about research that the University of Minnesota planned to conduct and be constructive about how to approach the problem from another perspective. Instead of continuing their research as first planned, the researchers from Minnesota reached out to a number of tribal 
entities and not only received input from them, but also participation and labor. They utilized traditional cultural knowledge to map and locate wild rice beds in the region and document them for future research. The University also ended up respecting the tribes wishes and stopped conducting genetic testing on wild rice.

In Wisconsin, a number of archaeological research projects are being conducted with full support and participation from the tribes. This decolonization of the field is leading to increased participation from a group of people that had once felt alienated and isolated from the research projects. They were able to regain their voice in the matters and control over the narrative of the research.

\section{Conclusions}

While these are some of the more prominent examples of a downside to cultural resource management, they are not the only ones. Most, if not all, CRM projects do not conduct additional consultation beyond what is required by law. It is because of this legal but limited practice that I argue such projects are not conducting a holistic, thorough research of the region. Archaeologists should consider tribal viewpoints and actively work towards adjusting their writing and assessments to incorporate these perspectives. Not only are these people descendants of the same groups under study, but also they provide insights and additional knowledge that could be more deeply considered by scholars.

The lack of consultation and collaboration in cultural resource management projects in the Northern Great Lakes Region leads to a biased colonialist perspective of Indigenous cultures and lifeways. It also prevents outsiders from understanding and further protecting Indigenous plant life and valuable landscapes that many Indigenous tribal groups view as important and as culturally significant. These landscapes have been the subject to intensive legal and social battles 
as many Indigenous groups from the Great Lakes region have fought for centuries to protect their rights to care for natural resources and continue their cultural traditions.

My review of the CRM reports shows almost zero collaboration or consultation documented within the reports, occurring on only one occasion. This likely lack of consultation can and will have negative impacts on future interpretation, as the researcher is purposefully ignoring a great source of information and ethical value of tribal stakeholders. The community members can to offer invaluable information about the cultural groups represented by the archaeological material, give visibility to Indigenous presence, and a fairer representation of the past.

What does this change in approach mean for archaeology? If current practices and examples within Indigenous archaeology are an example, we are looking at an increased amount of tribal support and assistance in archaeological projects. Indigenous activism has been advocating for increased Indigenous participation within the field along with attempts at changing the legislation that impacts archaeological resources and remains. One prominent example of this was the passing of the Native American Graves and Repatriation Act of 1990, which sought to return human remains to the tribal group with which they belong. This legislation was a huge win for Indigenous activists seeking to regain control over their ancestors. Recent movements advocate for increased collaboration and participation among Indigenous communities. Organizations such as the Indigenous Archaeology Collective and professional organizations such as the American Anthropological Association have made big strides in encouraging and training Indigenous communities in the processes of archaeology and strongly supporting increased collaboration with and focus on Indigenous communities and their concerns. 
Where does this lead us? This effort should foster a more holistic and complete view and approach towards archaeology and anthropology. This is a corrective action that needs to take place after centuries of ignorance and intentional or unintentional bias against Native communities. This initiative aims to be but a small step forward in the right direction of encouraging further Indigenous participation in creating and achieving research goals and working together to accomplish tribal goals as well. Research should not be a one-way extractive exercise in which the researcher takes the information but gives nothing back. A proper project is a two-way avenue of collaboration and free flowing ideas. The non-Indigenous person conducting the research can gain insight into a community that they wish to research, and in return, the tribe is able to accomplish some of their goals and needed investigations. Some examples of these beneficial goals are tribal nations trying to establish long-term occupations within a region or taking archaeological inventories of their reservation lands, including looking for lost or hidden remains. Recent examples of discoveries of hundreds of children's burials at Indian boarding schools are a good example of how archaeologists can work with a descendant community to help rectify mistakes of the past by offering expertise and experience in the repatriation of remains. This research is hopefully a step in the right direction of further incorporation of indigenous perspectives into contract archaeology. We've began to see implementation of community based participatory research on the academic side of archaeology, it is only a matter of time before it begins to be seen in cultural resources management. 


\section{REFERENCES}

Alex, Lynn Marie, Robert A. Alex, and Mark D. Fahrenbach. The Archeology of Beaver Creek Shelter (39CU779), Wind Cave National Park, South DAKOTA: A Preliminary Statement. Denver, CO: National Park Service, 1991.

Atalay, Sonya. Community-Based Archaeology: Research with, by, and for Indigenous and Local Communities. Berkeley: Univ. of California Press, 2012.

Atalay, Sonya L. "Global application of indigenous archaeology: community based participatory research in Turkey." Archaeologies 3, no. 3 (2007): 249-270.

Blaeser, Kimberly, "Wild Rice Rights: Gerald Vizenor and an Affiliation of Story,” in Centering Anishinaabeg Studies: Understanding the World Through Stories, ed. Jill Doerfler, Niigaanwewidam James Sinclair, and Heidi Kiiwetinepinesiik Stark (East Lansing: Michigan State Univ. Press, 2013), 237-57, 253.

Bouayad, Aurelien. "Wild rice protectors: An Ojibwe odyssey." Environmental Law Review 22, no. 1 (2020): 25-42.

Bruning, Susan B 2006 Complex Legal Legacies: The Native American Graves Protection and Repatriation Act, Scientific Study, and Kennewick Man. American Antiquity 71(3): 501-521

Caldwell, Warren W. The Black Partizan Site. Lincoln, Neb,, NE: River Basin Surveys, 1966.

Cheli, Elizabeth Louise. "Lithic Organization, Mobility, And Place-Making at the Frog Bay Site.” Thesis, ProQuest, 2020. 
Cleland, Charles Edward, and Marla Buckmaster. Lasanen Site: An Historical BURIAL Locality in Mackinac County, Michigan. East Lansing, MI: Michigan State University, 1971.

Creese, John, and Heather Walder. "From Wendake to Chequamegon: Bridging the Wendat Diaspora in Quimby’s Early Historic Period.” Occasional Papers 2 (2018): 33-54.

Deloria, Vine, and James A. Clifton. "Comfortable Fictions and the Struggle for Turf." American Indian Quarterly, vol. 16, no. 3, 1992, p. 397., doi:10.2307/1185800.

Dustin, F. (1932). Cranbrook Institute of Science Report on Indian Earthworks in Ogemaw County Michigan.

Erdrich, Louise. Books and islands in Ojibwe country. National Geographic Books, 2003.

Franzen, John G., Terrance J. Martin, and Eric C. Drake. "Sucreries and Ziizbaakdokaanan: Racialization, Indigenous Creolization, and the Archaeology of Maple-Sugar Camps in Northern Michigan." Historical Archaeology 52, no. 1 (2018): 164-196.

Gant, Robert D., and James H. Howard. Archeological Investigations at the ARP Site, 39BR101, Brule County, South Dakota, 1961. Vermillion, SD: W.H. Over Dakota Museum, University of South Dakota, 1967.

Hoffman, J. J. The La ROCHE SITES. Lincoln, Neb.: River Basin Surveys, Museum of Natural History, Smithsonian Institution, 1968.

Hurt, Wesley R. Report of the Investigations of the Four Bear Site, 39DW2, Dewey County, South Dakota, 1958, 1959. Lincoln, NE: River Basins Survey, 1961. 
Hurt, Wesley R., and Todd Willy. Report of the Investigation of the Rosa Site 39PO3, POTTER County, South DAKOTA, 1957, 1958.

Israel, Barbara A, et al. "Community-Based Participatory Research: Policy Recommendations for Promoting a Partnership Approach in Health Research.” Education for Health: Change in Learning \& Practice, vol. 14, no. 2, Jan. 2001, pp. 182-197., doi:10.1080/13576280110051055.

Johnston, Richard B. The Hitchell SITE. Lincoln, Neb: River Basin Surveys, 1967.

Karamanski, Theodore J., David J. Keene, Historical Use Study of White Deer Lake Camp, Marquette County, Michigan. 60 pp. report prepared by the Mid-American Research Center for the United States Forest Service, Eastern Region Office, 1980.

Katanski, Amelia V. "Stories that Nourish: Minnesota Anishinaabe Wild Rice Narratives." American Indian Culture and Research Journal 41, no. 3 (2017): 71-91.

Ketcherside, R. A. Cultural Resources Investigation of Three Archaeological Sites along the Roseau Flood Control Project: Roseau County, Minnesota. NORTH DAKOTA UNIV ARCHAEOLOGICAL RESEARCH GRAND FORKS, 1982.

Klein, Terry H., and Lynne Sebastian. In National Forum on Assessing Historic Significance for Transportation Programs: May 23-25, 1999, Washington, D.C. Washington, DC: Transportation Research Board, 2003. 
Kryder-Reid, E., \& Zimmerman, L. J. (2018). Of, By, and for Which People? Government and Contested Heritage in the American Midwest. In Cultural Contestation (pp. 239-262). Palgrave Macmillan, Cham.

Lankton, L. D. (2010). Hollowed ground: Copper mining and community building on Lake Superior, 1840s-1990s. Wayne State University Press.

Lehmer, Donald J., Warren W. Caldwell, Williams Joyce B., Jerry L. Livingston, and Paulette C. Workman. The Fire Heart Creek Site. Lincoln, Neb.: Smithsonian Institution, 1966.

Lehmer, Donald J., and David T. Jones. Arikara Archaeology: The Bad RIVER Phase by Donald J. Lehmer and David T. JONES. with Appendices BY T.M. Hamilton and William M. Bass. Editor: Jerome E. Petsche. Lincoln, Nebraska: Neb, 1968.

Liebmann, Matthew. "Demystifying the Big Horn Medicine Wheel: A contextual analysis of meaning, symbolism, and function." Plains Anthropologist 47, no. 180 (2002): 61-71.

Lightfoot, Kent G. "Culture Contact Studies: Redefining the Relationship between Prehistoric and Historical Archaeology." American Antiquity 60, no. 2 (1995): 199-217. https://doi.org/10.2307/282137.

Lowe, David C. Additional Material from and Notes on the Hog HOLLOW Site, Grant COUNTY, WISCONSIN. Ft. Belvoir: Defense Technical Information Center, 1986. 
Matson, Laura, G.-H. Crystal Ng, Michael Dockry, Madeline Nyblade, Hannah Jo King, Mark Bellcourt, Jeremy Bloomquist, et al. "Transforming Research and Relationships through Collaborative Tribal-University Partnerships on Manoomin (Wild Rice)." Environmental Science \& Policy 115 (2021): 108-15. https://doi.org/10.1016/j.envsci.2020.10.010.

McGowan, K., and G. R. Walz. "Cultural Resources and Land Use History Background Report On An Approximately 300-Acre Parcel Located In Saugatuck Township In Allegan County, Michigan. 48." (2017).

Mihesuah, Devon Abbott, ed. Natives and academics: Researching and writing about American Indians. U of Nebraska Press, 1998.

Milburn, Michael P. "Indigenous nutrition: Using traditional food knowledge to solve contemporary health problems." American Indian Quarterly (2004): 411-434.

Mueller, James W., Elizabeth Garland, Janet Brashler, Margaret Holman, Terrance Martin, and William A. Lovis. Phase II Completion Report: Major Problem Orientations in Michigan ARCHAEOLOGY: 1980-1984. Jackson, MI: Commonwealth Associates, Inc., 1980.

Mulholland, Susan. "Archaeological Excavation at the Fish Lake Dam Site: Year 2000." (2001).

Mulholland, Susan C., Stephen L. Mulholland, Jennifer R. Hamilton, and Stacey Stark. "Points and Pits: Archaeological Investigations in Minnesota's Region 9, the Lake Superior Shore, Carlton, Cook, Lake, and St. Louis Counties, Minnesota." (2011). 
Nesper, Larry. "Law and Ojibwe Indian 'Traditional Cultural Property' in the Organized Resistance to the Crandon Mine in Wisconsin." Law \& Social Inquiry 36, no. 01 (2011): 151-69. https://doi.org/10.1111/j.1747-4469.2010.01227.x.

Nicolai, Michele, Steve G. Sylvester, Kurt Schweigert, and Fred E. Schneider. Cultural Resource Investigation of the Goose River Basin, North Dakota. NORTH DAKOTA UNIV GRAND FORKS DEPT OF ANTHROPOLOGY AND ARCHAEOLOGY, 1978.

Overstreet, D. F. Archaeological Investigations at the Grant River Public Use Area. Volume 1. Narrative. GREAT LAKES ARCHAEOLOGICAL RESEARCH CENTER INC WAUKESHA WI, 1984.

Overstreet, David F., and Allen P. Van Dyke. Archaeological Reconnaissance of Lewiston and Portage Levees, Portage, Wisconsin. GREAT LAKES ARCHAEOLOGICAL RESEARCH CENTER INC MILWAUKEE WI, 1981.

Overstreet, David F. Archaeological Investigations, Navigation POOL II, Upper Mississippi River Basin. Wauwatosa, WI: Great Lakes Archaeological Research Center, 1985.

Park, LoriJo. "Archaeoastronomy on the Plains." The Journal of the South Dakota Archaeological Society Vol. 2 (1978).

Patterson, Kristine B., and Thomas Runge. "Smallpox and the Native American." The American Journal of the Medical Sciences, vol. 323, no. 4, 2002, pp. 216-222., doi:10.1097/00000441-200204000-00009. 
Peebles, Christopher Spalding, and Deborah Bush Black. The Distribution and Abundance of Archaeological Sites in the Coastal Zone of Michigan. Ann Arbor, MI: Div. of the Great Lakes, Museum of Anthropology, University of Michigan, 1976.

Ronda, J. P. Lewis, and Clark among the Indians: With a new introduction by the author. University of Nebraska Press. (2002).

Roth, B. J. An academic perspective on grey literature. Archaeologies, 6(2), 337-345. https://doi.org/10.1007/s11759-010-9141-9 (2010).

Rusch, Lynn A, and John T. Penman. Historic Sites Along The Great River Road. Madison: State Historical Society of Wisconsin. (1982)

Slay, John D. "Cultural Resources Management in the Black Hills.” The Journal of the South Dakota Archaeological Society Vol. 2 (1978).

Smith, G. Hubert. Big Bend Historic Sites. River Basin Surveys, Museum of Natural History, Smithsonian Institution, 1968.

Steere, B. A. Collaborative Archaeology as a Tool for Preserving Sacred Sites in the Cherokee Heartland. Indigeneity and the Sacred: Indigenous Revival and the Conservation of Sacred Natural Sites in the Americas, 22, 163. (2017).

Stone, Lyle M. Archaeological Investigation of the Marquette Mission Site, St. Ignace, MICHIGAN, 1971: A Preliminary Report. Lansing, Mich: Mackinac Island State Park Commission, 1972. 
Sturtevant, W. C. Handbook of North American Indians (Vol. 13 \& 15). Smithsonian Institution. (1978).

Sunseri, Jun, and Albert Gonzalez. "Honoring and Embodying the Mandate of CommunityAccountable Archaeology: Perspectives from the Indo-Hispano/a Southwest." Historical Archaeology 54, no. 4 (2020): 738-755.

Tuck, E., \& Yang, K. W. Decolonization is not a metaphor. Decolonization: Indigeneity, Education \& Society, 1(1), 1-40. (2012).

Wilson, John S. "We've got thousands of these! What makes an historic farmstead significant?." Historical Archaeology 24, no. 2 (1990): 23-33.

Zimmerman, Larry J. The Crow Creek Site (39BF11) Massacre: A Preliminary Report. Vermillion, South Dakota: USD Archeology Laboratory, U.S. Army Corps of Engineers, Orchard District, 1981. 